\title{
OPEN Transportin-2 plays a critical role in nucleocytoplasmic shuttling of oestrogen receptor- $\alpha$
}

\author{
Tetsuji Moriyama ${ }^{1}$, Yoshihiro Yoneda ${ }^{2,3}$, Masahiro Oka ${ }^{3,4} \&$ Masami Yamada ${ }^{1,5} \bowtie$
}

Oestrogen receptor- $\alpha(E R \alpha)$ shuttles continuously between the nucleus and the cytoplasm, and functions as an oestrogen-dependent transcription factor in the nucleus and as an active mediator of signalling pathways, such as phosphatidylinositol 3-kinase (PI3K)/AKT, in the cytoplasm. However, little is known regarding the mechanism of ER $\alpha$ nucleocytoplasmic shuttling. In this study, we found that ER $\alpha$ is transported into the nucleus by importin- $\alpha / \beta 1$. Furthermore, we found that Transportin-2 (TNPO2) is involved in 17 $\beta$-oestradiol (E2)-dependent cytoplasmic localisation of ER $\alpha$. Interestingly, it was found that TNPO2 does not mediate nuclear export, but rather is involved in the cytoplasmic retention of ER $\alpha$ via the proline/tyrosine (PY) motifs. Moreover, we found that TNPO2 competitively binds to the basic nuclear localisation signal (NLS) of ER $\alpha$ with importin- $\alpha$ to inhibit importin- $\alpha / \beta-$ dependent ER $\alpha$ nuclear import. Finally, we confirmed that TNPO2 knockdown enhances the nuclear localisation of wild-type ER $\alpha$ and reduces PI3K/AKT phosphorylation in the presence of E2. These results reveal that TNPO2 regulates nucleocytoplasmic shuttling and cytoplasmic retention of $E R \alpha$, so that $E R \alpha$ has precise functions depending on the stimulation.

Oestrogen receptor- $\alpha(E R \alpha)$ plays important roles in various physiological processes, such as male and female reproductive development, lipid and bone metabolism, and the maintenance of the cardiovascular and nervous systems $s^{1,2}$. ER $a$ proteins are primarily located in the nucleus, regardless of ligand binding, but shuttle constantly between the nucleus and the cytoplasm. Upon oestrogen binding, ER $a$ changes conformation that enables dimer formation and active transcription of target genes. Oestrogen-bound ERa has been reported to decrease shuttling and further accumulate in the nucleus ${ }^{3,4}$. Outside the nucleus, a small population of ERa is localised to the plasma membrane $e^{5}$, which requires palmitoylation, in interaction with the membrane protein caveolin- $1^{6}$. Oestrogenbound ERa on the plasma membrane can rapidly induce the mobilisation of intracellular calcium ${ }^{7}$ and activation of PI3K/AKT and MAPK/ERK pathways ${ }^{8-11}$. Abnormal phenotypes of nuclear-only ER $\alpha$ and membrane-only ER $\alpha$ transgenic mice suggested that normal organ development and function require convergence and crosstalk of the classical nuclear and extranuclear receptor pathways ${ }^{12-17}$. Moreover, the cytoplasmic ERa mutant, which forcibly changed the localisation of ER $\alpha$ to the cytoplasm, lost oestrogen-induced transcriptional responses, but still maintained MAPK/ERK activation ${ }^{18}$. Recently, cytoplasmic ER $\alpha$ mutant mice have been generated, and preliminary observations suggest that their phenotypes are similar to those of ERa deficient mice ${ }^{19}$. Therefore, nucleocytoplasmic shuttling plays an important role in the regulation of ER $\alpha$ signalling pathways.

Nucleocytoplasmic transport of macromolecules occurs through the nuclear pore complex (NPC), and is generally dependent on the presence of a specific signal sequence, called nuclear localisation signals (NLSs) and nuclear export signals (NESs). Many nucleocytoplasmic transport pathways are mediated by the importin- $\beta$ superfamily, which is composed of more than 20 family members in humans, and is functionally classified as importins and exportins. The importin- $\beta$ superfamily exhibits cargo specificity, but has the common features that recognise the NLS or NES sequences of cargo molecules and the GTP-bound form of Ran (RanGTP), a member of the Ras superfamily, and mediate transport between the nucleus and the cytoplasm ${ }^{20}$. Additionally, seven members of the importin- $\alpha$ family, which function as an adaptor between the NLS-containing cargo molecule

${ }^{1}$ Department of Cell Biology and Biochemistry, Division of Medicine, Faculty of Medical Sciences, University of Fukui, 23-3 Matsuoka Shimoaizuki, Eiheiji-cho, Yoshida-gun, Fukui 910-1193, Japan. ${ }^{2}$ Health and Nutrition (NIBIOHN), National Institutes of Biomedical Innovation, 7-6-8 Saito-Asagi, Ibaraki, Osaka 567-0085, Japan. ${ }^{3}$ Laboratory of Nuclear Transport Dynamics, Graduate School of Pharmaceutical Sciences, Osaka University, 1-6 Yamada-oka, Suita, Osaka 565-0871, Japan. ${ }^{4}$ Laboratory of Nuclear Transport Dynamics, National Institutes of Biomedical Innovation, Health and Nutrition (NIBIOHN), 7-6-8 Saito-Asagi, Ibaraki, Osaka 567-0085, Japan. ${ }^{5}$ Life Science Research Laboratory, University of Fukui, 23-3 Matsuoka Shimoaizuki, Eiheiji-cho, Yoshida-gun, Fukui 910-1193, Japan. ${ }^{\circledR}$ email: yamadama@u-fukui.ac.jp 
and importin- $\beta 1$, have been identified in humans ${ }^{21}$. Importin- $\alpha$ and importin- $\beta$ families have been reported to be involved in the nucleocytoplasmic shuttling of steroid hormone receptors. For instance, importin- $\alpha / \beta 1$ heterodimers, importin-7, importin-8, and importin-13 mediate nuclear import of glucocorticoid receptor (GR $)^{22-24}$. Importin- $\alpha / \beta 1$ heterodimers also mediate the nuclear import of mineralocorticoid receptor ${ }^{25}$ and androgen receptor (AR) ${ }^{26}$. Moreover, CRM1 (exportin-1) ${ }^{27}$ and exportin $-5^{28}$ can stimulate AR export. The distribution of thyroid hormone receptors is regulated by CRM1 $1^{29}$, exportin- 4 , exportin-5, and exportin- $7^{30}$. However, only a few studies have shown the nuclear export of $\mathrm{ERa}^{3,31,32}$; thus, the regulatory mechanism in ERa nucleocytoplasmic shuttling remains poorly understood.

Here, we sought to gain possible insights into the mechanism of ERa nucleocytoplasmic shuttling. We found that ER $\alpha$ is transported into the nucleus via two different pathways: active transport by importin- $\alpha / \beta 1$ and passive diffusion. Our results also show that Transportin-2 (TNPO2, importin-3) enhances the cytoplasmic localisation of ERa, not as a nuclear export receptor, but rather as a cytoplasmic retention factor, while it also competitively inhibits the binding of importin- $\alpha$. Furthermore, we confirmed that TNPO2 knockdown increased the nuclear localisation of endogenous ERa and suppressed PI3K/AKT activation in the presence of its ligand, 17 $\beta$-oestradiol (E2). We propose that TNPO2 plays a critical role in determining the distribution of ERa between the nucleus and the cytoplasm in response to stimulation.

\section{Results}

Oestrogen receptor- $\alpha$ enters the nucleus by two pathways: active transport by importin- $\alpha$ / $\beta 1$ and passive diffusion. ERa is predominantly localised in the nucleus, regardless of oestrogen. An NLS of ERa has been located within the DNA-binding domain (DBD) and the hinge region ${ }^{33,34}$. To determine the essential amino acid residues for ER $\alpha$ active nuclear transport, we introduced amino acid substitution mutations in the NLS region by converting the three basic amino acid clusters into alanine (Fig. 1A). Since the molecular weight of ERa is $\sim 66 \mathrm{kDa}$, which could pass the NPC by passive diffusion ${ }^{35}$, we first used ER $\alpha$ mutants with N-terminally fused GFP $(\sim 103 \mathrm{kDa})$ (Fig. 1B). When their subcellular distribution was determined in ERanegative HeLa cells after transient transfection, we observed a dominant nuclear localisation of wild-type ERa (GFP-ER $\alpha$ ). Slightly more GFP-tagged mutants of each cluster were found in the cytoplasm as compared with the wild type; however, they were mainly localised in the nucleus, which was further enhanced in the presence of E2. When ERa mutations were combined, GFP-ERa-m1, $\mathrm{m} 2$ were also predominantly localised in the nucleus, whereas GFP-ER $\alpha-\mathrm{m} 2, \mathrm{~m} 3$ showed a nuclear localisation disruption in the absence of E2; however, this mutant exhibited an increased proportion of nuclear localisation in the presence of E2. In contrast, GFP-ERa-m1, m3 and GFP-ERa-m1, m2, m3 were predominantly localised in the cytoplasm, regardless of the binding of E2. These data indicate that the basic amino acid clusters of both terminals of the NLS region of ERa are necessary and sufficient for ERa nuclear localisation. Therefore, we named ERa-m1, m3 as ERa-mNLS, a mutant defective in active nuclear transport (Fig. 2A). These basic amino acids of the NLS region are potentially recognised by importin- $\alpha$ as a classical NLS (cNLS), linking it to importin- $\beta 1$ to form the nuclear import complex. Therefore, we examined whether the basic amino acid clusters of ER $\alpha$ are recognised by importin- $\alpha 1$ (KPNA1), importin- $\alpha 2$ (KPNA2), importin- $\alpha 4$ (KPNA4) (Fig. 2B), or importin- $\beta 1$ (Supplementary Fig. 1) using a glutathione-S-transferase (GST) pulldown assay. In the absence of E2, whole cell lysates prepared from HeLa cells expressing a triple haemagglutinin $(3 \times \mathrm{HA})$-ER $\alpha$ or $3 \times \mathrm{HA}-\mathrm{ER} \alpha-\mathrm{mNLS}$ were incubated with recombinant GSTproteins. $3 \times \mathrm{HA}$-ER $\alpha$ interacted with GST-importin- $\alpha$, but $3 \times \mathrm{HA}$-ER $\alpha$-mNLS mostly did not. In contrast, $3 \times$ HA-ER $\alpha$ and $3 \times$ HA-ER $\alpha-m$ NLS were weakly or not at all bound to GST-importin- $\alpha 1$ and GST-importin- $\alpha 2$. To investigate whether importin- $\alpha / \beta 1$ mediates the nuclear import of ER $\alpha$, we subjected the GFP-tagged ER $\alpha$ amino acids 243-302 (GST-ERa-NLS-Hinge-GFP, Fig. 2A) to an in vitro transport assay using digitonin-permeabilized HeLa cells (Fig. 2C). When importin- $\alpha$ 4, importin- $\beta 1$, a small GTPase Ran, and ATP-regeneration system were exogenously supplied, GST-ER $\alpha$-NLS-Hinge-GFP was efficiently transported into the nucleus, whereas GST-ER $\alpha$-mNLS-Hinge-GFP was not transported. Nuclear transport by importin- $\alpha 4$ did not appear in the absence of importin- $\beta 1$, Ran, or the ATP-regeneration system (Supplementary Fig. 2). In contrast, in the case of other importin- $\alpha$ and in the absence of importin- $\alpha 4$, GST-ER $\alpha$-NLS-Hinge-GFP fluorescent signal was mainly located in the cytoplasm, whereas the nuclear GFP intensity was equal to that of the negative control (the condition without importin- $\alpha$ nor importin- $\beta 1$ ), in accordance with the weak binding of GST-importin- $\alpha 1$ and GST-importin- $\alpha 2$ to $3 \times$ HA-ERa. Moreover, cytoplasmic fluorescence could be suppressed by adding importin- $\alpha 4$. On the other hand, GST-ER $\alpha-m N L S-H i n g e-G F P$ showed faint cytoplasmic fluorescence, regardless of importin- $\alpha$ or importin- $\beta 1$ (see "Discussion" below). Together, these results indicate that importin- $\alpha 4$ recognises ER $\alpha$ through its basic amino acid clusters of the NLS region to form an ER $\alpha /$ importin- $\alpha 4 / \beta 1$ complex, and actively transports ERa into the nucleus in a Ran- and ATP-dependent manner. E2 treatment increased the binding of $3 \times$ HA-ER $\alpha$ to GST-importin- $\alpha 1$ (Fig. $2 \mathrm{~B}$ ), although there was almost no change in the binding between GST-importin- $\alpha 4$ and $3 \times$ HA-ER $\alpha$. Moreover, E2 treatment also enhanced the binding of $3 \times$ HA-ER $\alpha$ to GST-importin- $\beta 1$ (Supplementary Fig. 1). These data suggest that with E2 treatment, the importin- $\alpha / \beta 1$ heterodimer may facilitate ERa nuclear transport (see "Discussion" below).

Next, we analysed the subcellular distribution of $3 \times$ HA-ERa $(\sim 70 \mathrm{kDa})$, which is smaller than GFP-ERa, in HeLa cells. $3 \times$ HA-ER $\alpha$ was predominantly localised in the nucleus, corresponding to the distribution of GFP-ERa (Figs. 3A, 1B). On the other hand, $3 \times$ HA-ERa-mNLS was relatively abundant in the nucleus, which is obviously different from the distribution of GFP-ERa-mNLS (Figs. 3A, 1B), probably because of the size of the tag: GFP-ERa, but not $3 \times$ HA-ERa, was too large to passively diffuse through the NPC. These results suggest that endogenous $\mathrm{ER} \alpha$ can both actively shuttle and passively diffuse between the nucleus and the cytoplasm. 
A
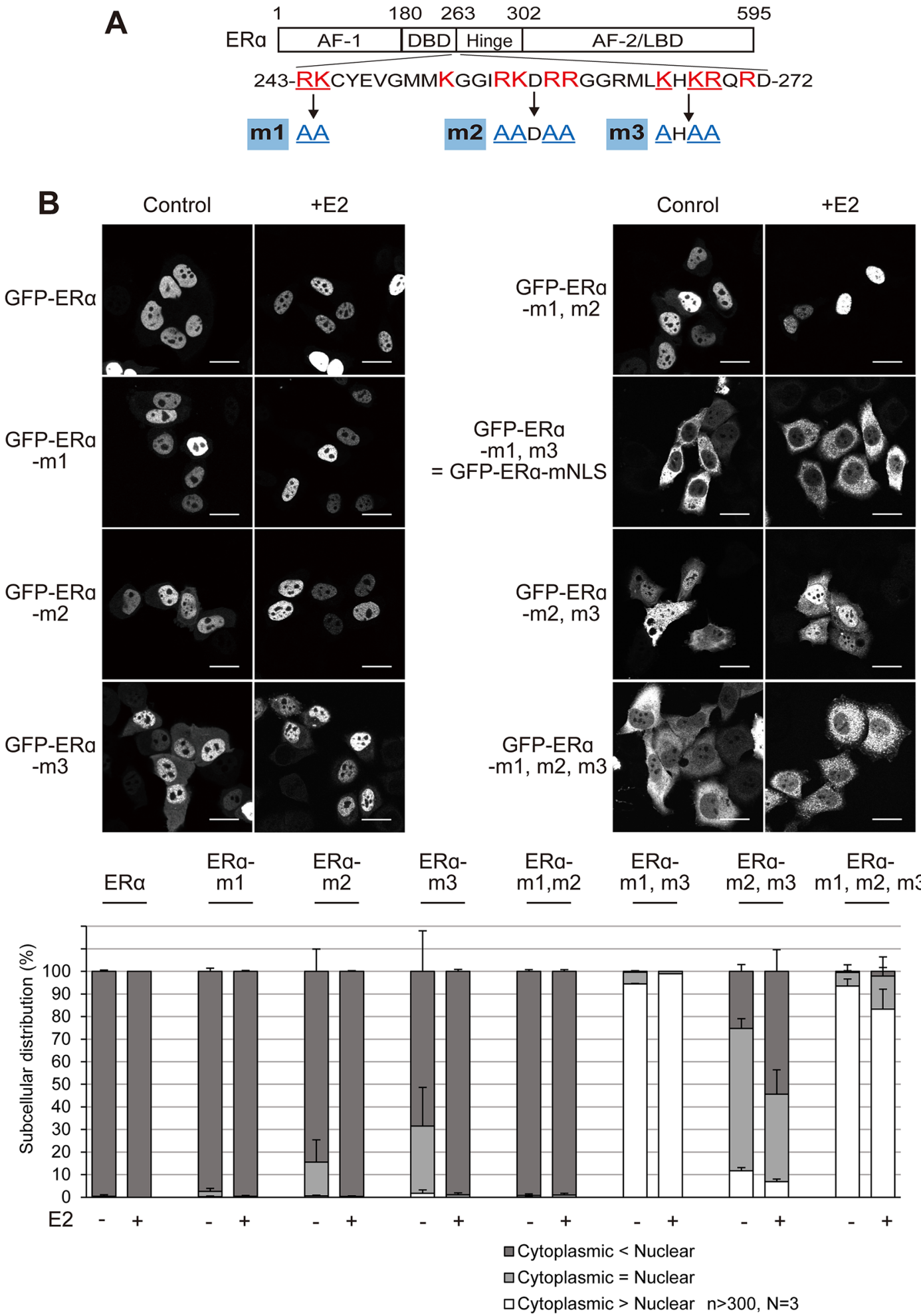

Figure 1. The subcellular distribution of GFP-ER $\alpha$ and the point mutants. (A) Schematic representation of the ERa mutants. The diagram shows the full-length ERa, and the positions of the DNA-binding domain (DBD), hinge region, ligand-binding domain (LBD), and the weak constitutive activation function (AF-1), and hormone-dependent activation function (AF-2) are indicated. The NLS straddles the DBD and hinge region. (B) Fluorescence images of GFP-ERa and the point mutants in HeLa cells, in the presence or absence of $10 \mathrm{nM}$ E2 for $3 \mathrm{~h}$. Scale bars, $20 \mu \mathrm{m}$. The subcellular distribution (\%) of GFP-ERa and the point mutants was determined from the nuclear, nuclear and cytoplasmic, and cytoplasmic distribution, calculated from $>300$ transfected cells. Each data point represents the average of three independent experiments and the error bars denote the standard deviation. 


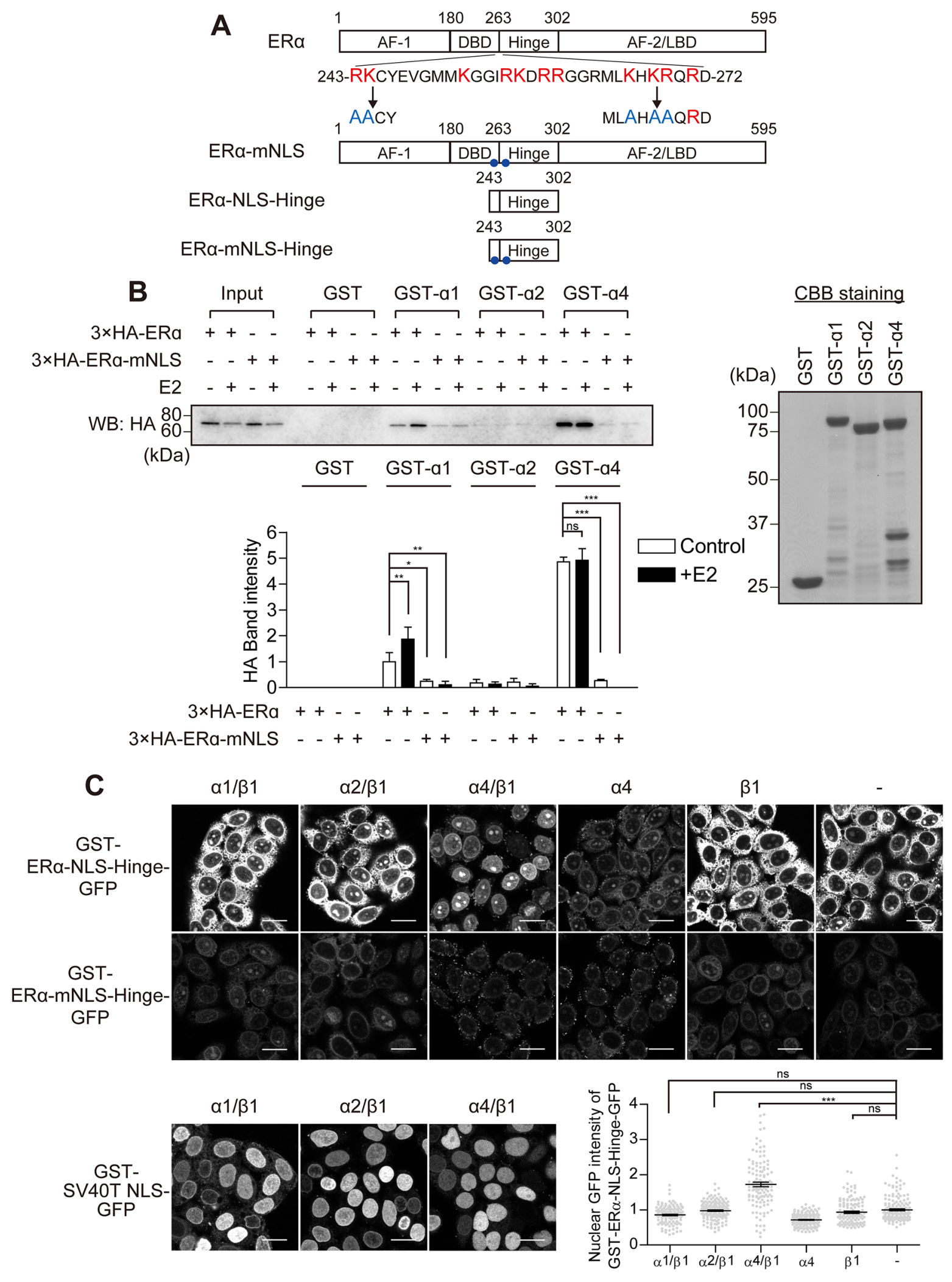


4Figure 2. The NLS of ER $\alpha$ is recognised by importin- $\alpha / \beta 1$. (A) Schematic representation of the ER $\alpha-N L S$ mutant (mNLS), ER $\alpha$-NLS-Hinge and ER $\alpha$-mNLS-Hinge. (B) Importin- $\alpha$ recognises the basic amino acids of ERa. GST pulldown assays were performed with recombinant GST, GST-importin- $\alpha 1$ (GST- $\alpha 1$ ), GST-importin- $\alpha 2$ (GST- $\alpha 2)$ and GST-importin- $\alpha 4$ (GST- $\alpha 4)$, using HeLa lysates expressing $3 \times$ HA-ER $\alpha$ or $3 \times$ HA-ERa-mNLS, in the presence or absence of $10 \mathrm{nM} \mathrm{E2}$. CBB stain was used as the loading control for the reaction. The average band intensity of $3 \times$ HA-ER $\alpha$ bound to GST-importin- $\alpha 1$ in the absence of E2 was set to 1 . Each data point represents the average of four independent experiments and the error bars denote the standard deviation. ${ }^{\star} P<0.05,{ }^{\star \star} P<0.01,{ }^{\star \star \star} P<0.001$; ns, not significant; as determined by one-way ANOVA followed by Tukey's multiple comparison test. Full-length images of western blot and CBB staining are shown in Supplementary Fig. 9. (C) An in vitro transport assay was performed for measuring the nuclear import of GFP-conjugated GST-ER $\alpha$-NLS-Hinge or GFP-conjugated GST-ER $\alpha$-mNLS-Hinge, with or without importin- $\alpha$ or importin- $\beta 1$. The assay was performed in the presence of RanGDP and an ATP-regenerating system containing GTP. GST-SV40T NLS-GFP was used as the positive control. Scale bars, $20 \mu \mathrm{m}$. The graphs depict the intranuclear GFP fluorescence intensity of GST-ERa-NLS-Hinge-GFP calculated from the average of at least 120 cells and the error bars denote the respective standard error. ${ }^{\star * \star} P<0.001$; ns, not significant; as determined by Kruskal-Wallis test and Dunn's multiple comparison test. The average nuclear intensity without importin- $\alpha$ and importin- $\beta 1$ was set to 1 .

E2 induces an ER $\alpha$-NLS mutant to translocate into the cytoplasm. We investigated the effect of E2 treatment on the subcellular distribution of ER $\alpha$. $3 \times$ HA-ER $\alpha$ showed only a slight change, but $3 \times$ HA-ERamNLS was dramatically translocated to the cytoplasm by E2 treatment (Fig. 3A). The alteration of the distribution pattern started within 30 min after E2 treatment and was increasingly prevalent in the cytoplasm as the time course progressed (Fig. 3B). To exclude the possibility of enhanced degradation of $3 \times$ HA-ER - -mNLS caused by $\mathrm{E} 2$ treatment, $3 \times \mathrm{HA}-\mathrm{ER} \alpha-\mathrm{mNLS}$ protein levels of unstimulated and E2-stimulated cells were compared between the 15 and 180 min time points. E2 had no visible effect on the $3 \times$ HA-ER $\alpha$-mNLS protein levels (Fig. 3C).

Next, we tested whether $3 \times$ HA-ER $\alpha-$ mNLS nuclear export occurs in a passive diffusion process. Incubation of intact cells at a low temperature allows for passive diffusion through the NPC ${ }^{36,37}$. HeLa cells transfected with $3 \times$ HA-ER $\alpha$-mNLS were incubated at $4{ }^{\circ} \mathrm{C}$ or $37^{\circ} \mathrm{C}$ with E2 for $1 \mathrm{~h}$. As shown in Fig. 3D, $3 \times$ HA-ER $\alpha$-mNLS nuclear export was inhibited at low temperature, suggesting that $3 \times \mathrm{HA}-\mathrm{ER} \alpha-\mathrm{mNLS}$ is exported into the cytoplasm via a temperature-sensitive transport mechanism, rather than by passive diffusion.

Previous reports showed that CRM1, which is a ubiquitous nuclear export receptor, mediates ERa nuclear export $^{3,31}$. To examine whether the E2-dependent cytoplasmic localisation of $3 \times$ HA-ERa-mNLS is mediated by CRM1, HeLa cells were transfected with $3 \times$ HA-ER $\alpha-$ mNLS and treated with leptomycin B (LMB), an inhibitor of CRM1-dependent nuclear export ${ }^{38}$. As shown in Supplementary Fig. 3A, LMB did not prevent the alteration of the distribution pattern of ERa-mNLS in the presence of E2, whereas it inhibited the nuclear export of endogenous RanBP1 as previously reported ${ }^{36}$. These contrasting results on the LMB effect in the subcellular localisation of ERa are probably caused by the NLS mutant used in this study instead of the wild type ERa used in the previous reports. Therefore, it is possible that the imbalance in ERa-mNLS transport allowed us to observe the nuclear export more clearly. Meanwhile, we confirmed the binding of recombinant GST-CRM1 and $3 \times$ HA-ER $\alpha-$ mNLS exogenously expressed in HeLa cells using a GST pulldown assay, as described previously ${ }^{32}$ (Supplementary Fig. 3B). Hence, we could not exclude the possibility of ER $\alpha$ nuclear export in a CRM1-dependent manner.

Transportin-2 is required for the E2-induced cytoplasmic localisation of the ER $\alpha$-NLS mutant, but does not function as its nuclear export receptor. We speculated that the importin- $\beta$ superfamily mediated ER $\alpha$ export. Therefore, to further study the E2-dependent ERa export mechanism, we investigated the effect of siRNA against importin- $\beta$ family genes, calreticulin ${ }^{39,40}$ and hikeshi (Hsp70s import receptor $)^{41}$ genes using $3 \times$ HA-ER $\alpha-m N L S$, as a useful tool to easily observe ER $\alpha$ export. The knockdown efficiency of the corresponding siRNAs was determined using quantitative real-time PCR analysis (Supplementary Fig. 4A) and western blotting for some of the importin- $\beta$ family members (Supplementary Fig. 4B). After E2 treatment, we examined the subcellular distribution of $3 \times$ HA-ER $\alpha$-mNLS in siRNA-transfected HeLa cells using immunofluorescence. We found that Transportin-2 (TNPO2, importin-3) siRNA-knockdown led to a strong inhibition of the E2-induced cytoplasmic localisation of $3 \times \mathrm{HA}-\mathrm{ER} \alpha$-mNLS, whereas the other genes did not significantly affect its location (Fig. 4A,B). Next, to validate the binding between TNPO2 and ER $\alpha$, we performed recombinant GST-TNPO2 pulldowns from E2-treated or untreated HeLa cells expressing $3 \times$ HA-ERa-mNLS. In the absence of E2, $3 \times \mathrm{HA}-\mathrm{ER} \alpha-\mathrm{mNLS}$ only slightly interacted with GST-TNPO2, but this interaction was strongly increased by E2 treatment (Fig. 4C). The binding of exportins to cargo molecules is greatly enhanced by RanGTP ${ }^{42-44}$. However, $3 \times$ HA-ERa-mNLS unexpectedly failed to bind to GST-TNPO2 in the presence of the GTPase-deficient mutant RanQ69L (GTP-form) (Fig. 4C), indicating that TNPO2 does not function as a conventional export receptor for $3 \times$ HA-ERa-mNLS. Furthermore, GFP-ER $\alpha$-mNLS was largely restricted to the cytoplasm in the absence or presence of E2 (Fig. 1B), implying that TNPO2 is not an ERa import receptor. Together, these results indicate that TNPO2 is required for the E2-induced cytoplasmic localisation of ERamNLS but does not mediate its nuclear export.

Transportin-2 binds to ER $\alpha$ via two PY-motifs in the AF-1 domain and facilitates ER $\alpha$ localisation to the cytoplasm in an E2-dependent manner. TNPO2 has been reported to recognise consensus sites of cargo molecules containing a characteristic proline/tyrosine (PY) motif ${ }^{45}$, which possesses a central hydrophobic ( $\Phi$-G/A/S- $\Phi \Phi, \Phi$ is a hydrophobic residue) or basic motif, followed by a C-terminus 
A
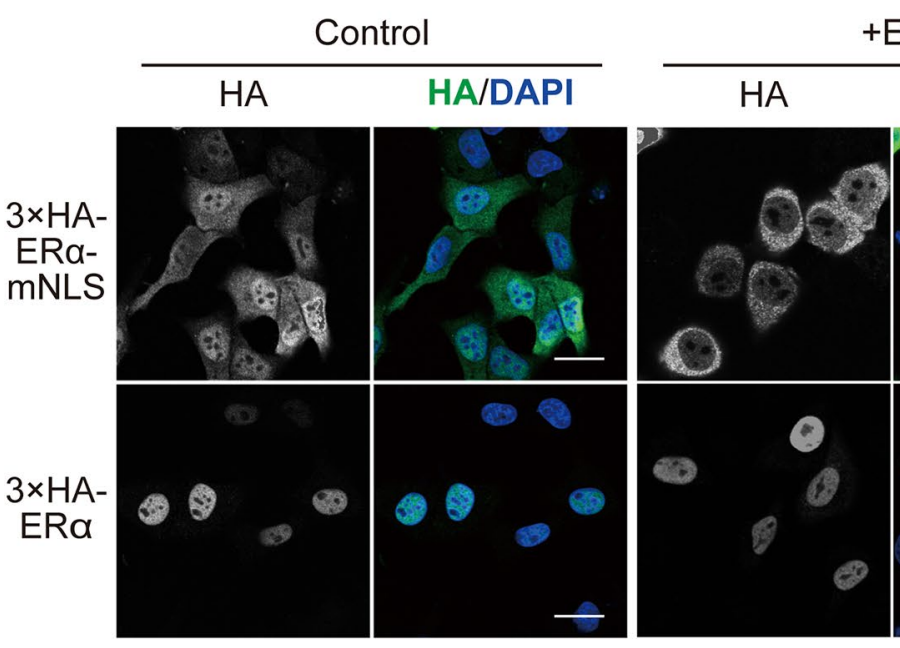

$+\mathrm{E} 2$

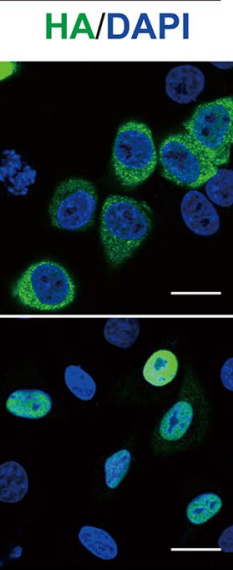

$3 \times \mathrm{HA}-$

ERa

ERa-

mNLS

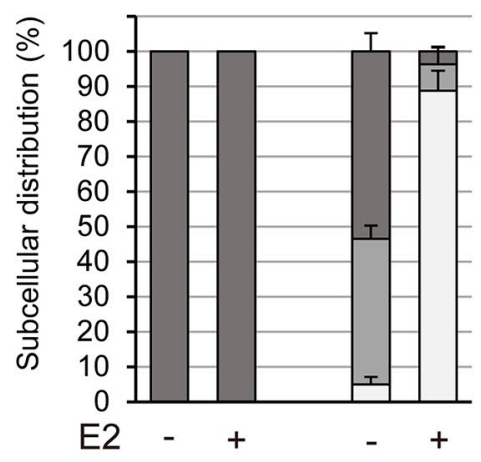

$\square$ Cytoplasmic < Nuclear

$\square$ Cytoplasmic $=$ Nuclear

$\square$ Cytoplasmic $>$ Nuclear $n>300, N=3$

B

$+\mathrm{E} 2$
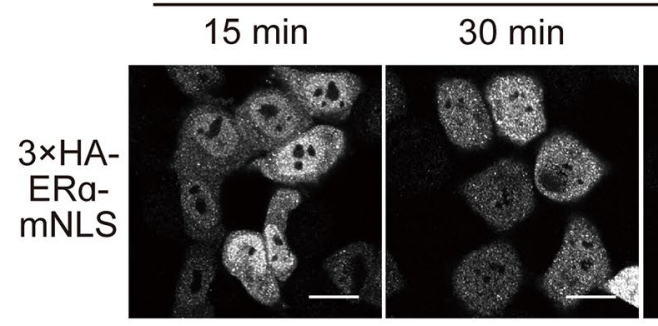

$60 \mathrm{~min}$

$180 \mathrm{~min}$
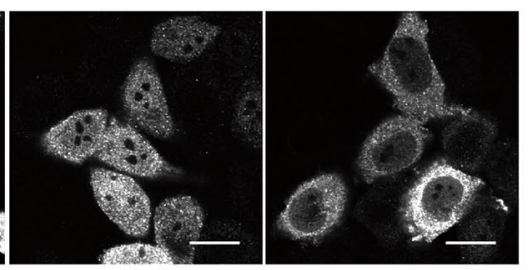

C
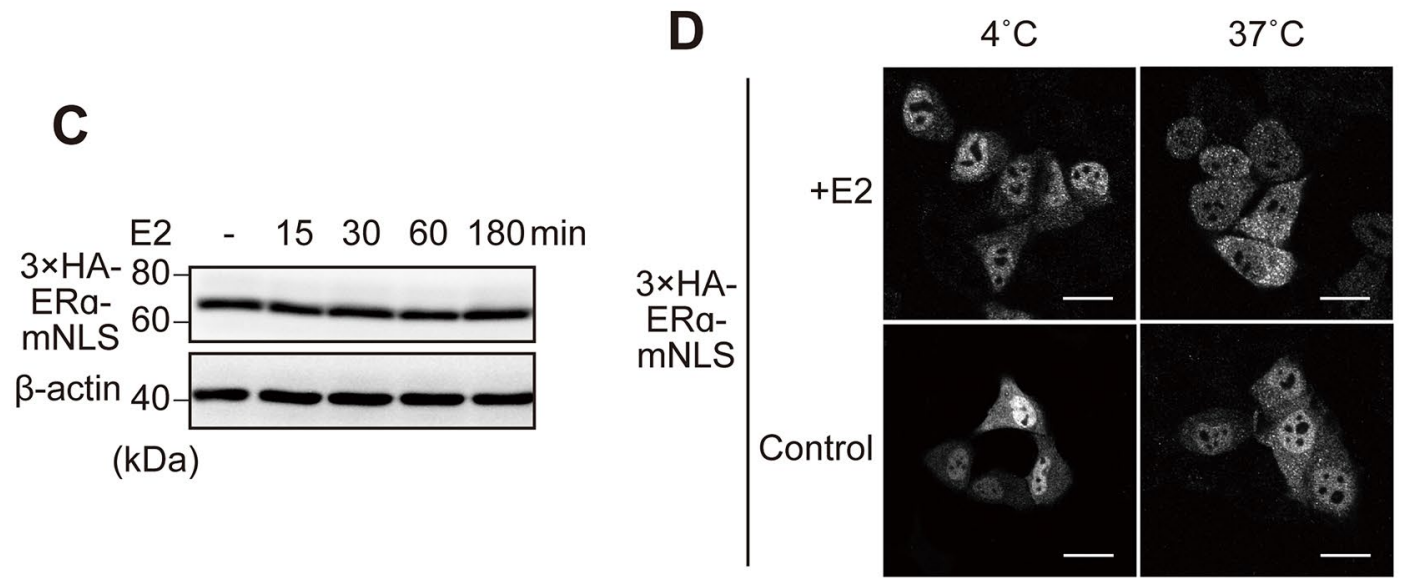

Figure 3. E2 induces cytoplasmic localisation of ERa-mNLS. (A) Immunofluorescence images of $3 \times \mathrm{HA}-\mathrm{ER} \alpha$ and $3 \times$ HA-ERa-mNLS in HeLa cells, in the presence or absence of $10 \mathrm{nM}$ E2 for $3 \mathrm{~h}$. The cells were immunostained for HA (green) and stained with DAPI (blue). Scale bars, $20 \mu \mathrm{m}$. The subcellular distribution (\%) of GFP-ERa and the point mutants was determined from the nuclear, nuclear and cytoplasmic, and cytoplasmic distribution, calculated from $>300$ transfected cells. Each data point represents the average of three independent experiments and the error bars denote the standard deviation. (B) Immunofluorescence images of $3 \times$ HA-ER $\alpha-m N L S$ in HeLa cells treated with $10 \mathrm{nM}$ E2 for the indicated durations. The cells were immunostained for HA. Scale bars, $20 \mu \mathrm{m}$. (C) Treatment with E2 did not affect the steady-state expression levels of $3 \times$ HA-ERa-mNLS. HeLa cells expressing $3 \times$ HA-ERa-mNLS were treated with $10 \mathrm{nM}$ E2 for the indicated durations. Following treatment, the cells were lysed and subjected to SDS-PAGE. Western blotting was performed with an anti-HA antibody. $\beta$-actin was used as the loading control. Full-length images of western blots are shown in Supplementary Fig. 10. (D) The nuclear export of $3 \times$ HA-ERa-mNLS was inhibited at a lower temperature. HeLa cells expressing $3 \times \mathrm{HA}$-ERa-mNLS were treated with $10 \mathrm{nM} \mathrm{E} 2$ and incubated at $4{ }^{\circ} \mathrm{C}$ or $37^{\circ} \mathrm{C}$ for $1 \mathrm{~h}$ and were immunostained for HA. Scale bars, $20 \mu \mathrm{m}$. 
$\mathrm{R} / \mathrm{H} / \mathrm{K}-\mathrm{X}(2-5)-\mathrm{P}-\mathrm{Y}$ ( $\mathrm{X}$ is any residue) consensus sequence ${ }^{46}$. The $61-180$ residues of the AF-1 domain of ERa contain two similar PY-motifs: 64-AAAAANAQVYGQTGLPY-80 and 117-LSPFLQPHGQQVPY-130. First, in order to clarify the relationship between ERa and TNPO2, we generated two deletion mutants lacking the AF-1 domain of ERa-mNLS, residues-61-595 (ERa $\Delta 1$-mNLS) and 181-595 (ERa $\Delta 2$-mNLS), respectively (Fig. 5A, left panel), and examined their binding to GST-TNPO2 and their subcellular distributions. The GST pulldown assay showed that exogenously expressed $3 \times$ HA-ERa-mNLS and $3 \times$ HA-ERa $\Delta 1$-mNLS in HeLa cells had higher binding to recombinant GST-TNPO2 after E2 treatment, whereas $3 \times$ HA-ERa $\Delta 2$-mNLS showed only little binding capacity (Fig. 5B, left panel). Immunofluorescence staining showed that $3 \times$ HA-ERa $\Delta 1$-mNLS and $3 \times$ HA-ERa $\Delta 2$-mNLS were relatively abundant in the nucleus in the absence of E2, similar to $3 \times$ HA-ERamNLS (Supplementary Fig. 5A). However, after E2 treatment, $3 \times$ HA-ER $\alpha \Delta 1$-mNLS was still translocated to the cytoplasm, while $3 \times \mathrm{HA}-\mathrm{ER} \alpha \Delta 2$-mNLS was not (Fig. $5 \mathrm{C}$, left panel). These results indicate that the AF-1 domain of ERa (amino acids 61-180), which includes two putative PY-motifs, is required for E2-dependent binding to TNPO2 and for ERa-mNLS localisation to the cytoplasm. To further clarify this, we constructed a double PY-motifs mutant (mPYs) that replaced the PY-motif (P79/Y80 and P129/Y130) with alanine (Fig. 5A, right panel). As expected, $3 \times \mathrm{HA}-\mathrm{ER} \alpha-\mathrm{mNLS}$-mPYs exogenously expressed in HeLa cells almost lost the ability to interact with recombinant GST-TNPO2 in the GST pulldown assay (Fig. 5B, right panel). Moreover, it obviously reduced the cytoplasmic localisation in the presence of E2, compared with $3 \times$ HA-ERa-mNLS (Fig. 5C, middle panel). In the absence of E2, $3 \times \mathrm{HA}-\mathrm{ER} \alpha$-mNLS-mPYs was relatively abundant in the nucleus, similar to $3 \times$ HA-ERa-mNLS (Supplementary Fig. 5B). Next, we investigated the effect of the M9 transport signal, which is a transportin-specific substrate ${ }^{47,48}$, on the subcellular distribution of $3 \times$ HA-ERa-mNLS. In mCherry-M9 transfected HeLa cells, the cytoplasmic localisation of $3 \times$ HA-ER $\alpha-m$ NLS was suppressed, remaining mainly in the nucleus regardless of E2 (Fig. 5D). These data indicate that TNPO2 facilitates the cytoplasmic localisation of ERa-mNLS by binding to PY-motifs of ERa in an E2-dependent manner.

Transportin-2 competes with importin- $\alpha$ for binding to the NLS region of ER $\alpha$. Next, we investigated the binding of wild-type ER $\alpha$ and its deletion mutant lacking the AF-1 domain (ERa $\Delta 2)$ (Fig. 6A) to TNPO2, using a GST pulldown assay. Unexpectedly, both full-length ER $\alpha$ and ER $\alpha 2$, despite not having the two PY-motifs, increased the binding to recombinant GST-TNPO2 after E2 treatment (Fig. 6B). This result suggests that TNPO2 can directly or indirectly bind to the basic NLS region and/or PY-motifs region of ERa in an E2-dependent manner. Since importin- $\alpha$ recognises the NLS region of ERa (Fig. 2B), we examined whether TNPO2 directly completes importin- $\alpha$ off the preformed importin- $\alpha$-ER $a$ complex. For this purpose, GSTimportin- $\alpha 1$ or GST-importin- $\alpha 4$ bound to glutathione Sepharose beads were first incubated with whole cell lysates prepared from E2-treated HeLa cells expressing $3 \times$ HA-ER $a$ protein, and then recombinant TNPO2 was added to the reactions. As shown in Fig. 6C, E2-bound ERa was dissociated from GST-importin- $\alpha 4$ by the addition of TNPO2 in a dose-dependent manner. Similarly, GST-importin-a1 slightly released E2-bound ER $\alpha$ upon TNPO2 addition in a dose-dependent manner. To rule out the possibility that TNPO2 directly binds to importin- $\alpha$ and destabilises the preformed importin- $\alpha$-ER $\alpha$ complex, we checked for their direct interaction using a GST pulldown assay. We found that recombinant $3 \times$ Flag-importin- $\alpha 1$ and $3 \times$ Flag-importin- $\alpha 4$ did not interact significantly with recombinant GST-TNPO2 (Supplementary Fig. 6). Collectively, these data demonstrate that, in the presence of E2, TNPO2 binds competitively with importin- $\alpha$ to the basic NLS region of ERa.

Transportin-2 is required for cytoplasmic retention of ER $\alpha$ and concomitant AKT activation. Previous studies demonstrated that, in addition to regulation of the target gene expression, E2-bound $\mathrm{ER} \alpha$ can rapidly stimulate the cytoplasmic signalling pathways, including PI3K/AKT ${ }^{8,11}$. Given that TNPO2 could bind to two PY-motifs of ERa in the cytoplasm and competitively bind to importin- $\alpha$ in its basic NLS region in an E2-dependent manner, we speculated that TNPO2 may function in the cytoplasmic retention of ERa to induce cytoplasmic signalling pathways. To further investigate the role of TNPO2 in the regulation of ERa localisation, we co-transfected HeLa cells with $3 \times \mathrm{HA}-\mathrm{ERa}$ and $3 \times$ Flag-TNPO2 expression vectors. Immunofluorescence staining showed that $3 \times \mathrm{HA}-\mathrm{ER} \alpha$ was mainly localised in the nucleus of untreated HeLa cells, with or without co-expression of $3 \times$ Flag-TNPO2. However, upon E2 treatment for $10 \mathrm{~min}, 3 \times \mathrm{HA}-\mathrm{ER} \alpha$ shifted more to the cytoplasm when the $3 \times$ Flag-TNPO2 was co-expressed, as compared with $3 \times$ HA-ER $\alpha$ only (Fig. 6D). Additionally, overexpression of TNPO2 in ERa-positive MCF-7 cells caused a noticeable change in the subcellular distribution of endogenous ERa from the nucleus to the cytoplasm after E2 treatment for $10 \mathrm{~min}$ (Supplementary Fig. 7). Conversely, the suppression of TNPO2 caused an increase in the nuclear endogenous ERa compared with the control cells (Fig. 6E, Supplementary Fig. 8A). These data suggest that TNPO2 functions as a cytoplasmic retention factor for ERa in an E2-dependent manner. Additionally, as shown in Supplementary Fig. 8B, TNPO2 was localised on the plasma membrane and colocalised with ERa in MCF-7 cells, both of which were diminished upon TNPO2 knockdown (see "Discussion" below). To verify the role of TNPO2 in E2-bound ER $\alpha$-mediated cytoplasmic signalling, we knocked down TNPO2 expression in MCF-7 cells, followed by E2 treatment and assessed the activation of AKT. As shown in Fig. 6F, an increase in AKT phosphorylation was observed in control cells after 15 min of E2 treatment, but not in TNPO2 knockdown cells, indicating that $\mathrm{TNPO} 2$ is required for E2-induced activation of AKT.

\section{Discussion}

Oestrogen receptors belong to the steroid hormone receptor superfamily. The nucleocytoplasmic transport mechanism of steroid hormone receptors has been extensively studied, and many have been reported to involve the importin family $21,23,24,29,46$. However, ERa nuclear transport has still not been clarified. Here, our data provide evidence that ER $\alpha$ is recognised by importin- $\alpha 4$ through its basic amino acid clusters of the NLS region to form 
Figure 4. TNPO2 is necessary for the E2-induced cytoplasmic localisation of ERa-mNLS, but does not function as a nuclear export receptor. (A) The effect of knockdown of the importin- $\beta$ family, calreticulin, or hikeshi on the subcellular distribution of $3 \times$ HA-ERa-mNLS. HeLa cells were transfected with siRNAs against the importin- $\beta$ family, hikeshi, and calreticulin. The next day, the cells were transfected with plasmids expressing $3 \times$ HA-ER $\alpha$-mNLS. The cells were subsequently treated with $10 \mathrm{nM}$ E2 for $2 \mathrm{~h}$ and immunostained for HA. The subcellular distribution (\%) of $3 \times$ HA-ER $\alpha-m N L S$ was determined from the nuclear, nuclear and cytoplasmic, and cytoplasmic distribution, calculated from $>300$ transfected cells. Each data point represents the average of results obtained from three independent experiments and the error bars denote the standard deviation. (B) Immunofluorescence images of $3 \times$ HA-ERa-mNLS in HeLa cells transfected with TNPO2specific siRNAs, in the presence or absence of $10 \mathrm{nM}$ E2 for $2 \mathrm{~h}$. The cells were immunostained for HA. Scale bars, $20 \mu \mathrm{m}$. (C) TNPO2 recognises $3 \times$ HA-ERa-mNLS in an E2-dependent and RanGTP-sensitive manner. GST pulldown assays were performed with recombinant GST, GST-importin- $\beta 1$ and GST-TNPO2, using HeLa lysates expressing $3 \times \mathrm{HA}-\mathrm{ER} \alpha-\mathrm{mNLS}$, in the presence or absence of $2 \mu \mathrm{M}$ recombinant $6 \times$ His-RanQ69L. GSTimportin- $\beta 1$ was used as the negative control. \#, non-specific band. CBB stain was used as the loading control for the reaction. The average band intensity of $3 \times$ HA-ERa-mNLS bound to GST-TNPO2 in the presence of E2 was set to 1 . Each data point represents the average of four independent experiments and the error bars denote the standard deviation. ${ }^{\star *} P<0.01,{ }^{* *} P<0.001$ as determined by one-way ANOVA followed by Tukey's multiple comparison test. Full-length images of western blots and CBB staining are shown in Supplementary Fig. 11.

an ER $\alpha /$ importin- $\alpha 4 / \beta 1$ complex, and can enter the nucleus via active transport. In addition, our observations support the hypothesis that ERa can passively diffuse between the nucleus and the cytoplasm. Furthermore, we have demonstrated that TNPO2 regulates the subcellular distribution of ERa through cytoplasmic retention and competitive inhibition with importin- $\alpha$ in an E2-dependent manner, activating the function of ER $\alpha$ in the cytoplasm as an active mediator of signalling pathways (Fig. 7).

So far, it has been reported that some importins could inhibit the nuclear transport mediated by other importins. For example, importin- $\alpha$ inhibits the nuclear import of Snail mediated by importin- $\beta 1^{49}$. Importin- $\alpha 2$ plays a role in the cytoplasmic retention of Oct6 and Brn2 transcription factors in undifferentiated mouse embryonic stem cells ${ }^{50}$. Importin-7 has also been reported to inhibit the nuclear import of AR by importin- $\alpha /$ $\beta 1^{51}$. We recently found that importin- $\alpha 8$ (KPNA7) forms heterodimers with other importin- $\alpha$, and proposed that importin- $\alpha 8$ can suppress cNLS binding through hetero-dimerization ${ }^{52}$. Here, we found that TNPO2 could competitively inhibit the nuclear import of ER $\alpha$ by importin- $\alpha / \beta 1$. The transportin subfamily was first suspected to act as a nuclear bidirectional receptor; however, subsequent studies refuted this hypothesis. It is thought that the transportin subfamily in nucleocytoplasmic transport is restricted to nuclear import ${ }^{45}$. As a typical example, TNPO1 and TNPO2 mediate nuclear import of heterogeneous nuclear ribonucleoprotein (hnRNP) A1 through the interaction of the M9 transport signal. However, even though M9 is known to serve as a bidirectional signal, a nuclear export receptor that recognises M9 is yet to be identified ${ }^{53,54}$. Interestingly, similar to our results, transportin can bind to Deleted in breast cancer 1 (DBC-1) with and without NLS ${ }^{55}$. Therefore, the transportin subfamily may play a role in the regulation of cytoplasmic signalling as well as in nuclear transport.

Of note, our data show that TNPO2 is localised on the plasma membrane and colocalises with ERa in MCF-7 cells, both of which were diminished in TNPO2 knockdown cells (Supplementary Fig. 8B). Therefore, we speculate that TNPO2 may play an important role in ERa translocation to the plasma membrane and promote association with partner proteins, such as IGF- $1 \mathrm{R}^{9}, \mathrm{Shc}^{56}, \mathrm{HER}-2^{10}$, and EGFR ${ }^{11}$. In the future, an accurate understanding of the cytoplasmic roles of the transportin subfamily may provide insight into the novel regulatory mechanism of the biological function of transportin-cargos.

$\mathrm{ERa}$ is mainly localised in the nucleus, regardless of the ligand. We have demonstrated that importin- $\alpha 4$ recognises ER $\alpha$ independent of E2 through the basic NLS region. In addition, the importin- $\alpha 4 / \beta 1$ heterodimer can effectively import the basic NLS-containing fragment of ERa in an in vitro transport assay, in the presence of Ran and ATP. These data strongly indicate that the importin-a4 subtype constitutively contributes to the nuclear localisation of ER $\alpha$. Moreover, E2 treatment increased the binding of ER $\alpha$ to importin- $\beta 1$ (Supplementary Fig. 1), which raises the possibility that E2 may induce the formation of ER $\alpha /$ importin- $\alpha 4$ /importin- $\beta 1$ complex, and promote its nuclear transport. Notably, in the in vitro transport assay, lack of importin- $\alpha 4$ resulted in a pronounced localisation of GST-ERa-NLS-Hinge-GFP to the cytoplasm. Cytoplasmic fluorescence could be suppressed by importin- $\alpha 4$ addition or mutating in the basic amino acids of the NLS. Previous studies have shown that basic proteins aggregate in an importin-free cytosol, apparently through multivalent ionic interactions with cytoplasmic polyanions, such as tRNA ${ }^{57}$. Our results also have led to the idea that importin- $\alpha 4$ may have another function as a cytoplasmic chaperone for the exposed domains with basic charges of ERa.

Oestrogen has been reported to induce nuclear accumulation of $\mathrm{ERa}^{33,34}$. Interestingly, the GST pulldown assay showed that E2 treatment increased the binding between ER $\alpha$ and importin- $\alpha 1$ but did not affect the binding between ER $\alpha$ and importin- $\alpha 4$ (Fig. 2B). Similarly, importin- $\beta 1$ increased the interaction with ERa in response to E2 (Supplementary Fig. 1). These results imply that, in addition to the NLS region, importin- $\alpha 1$ may recognise other region(s) or additional cofactor(s) depending on the conformational change induced by E2 treatment. Thus, the nuclear transport of importin- $\alpha 1 / \beta 1$ may be particularly important for the nuclear accumulation of ER $\alpha$ via E2 treatment. Previously, we generated and examined knockout (KO) mice lacking importin- $\alpha 1^{58}$. The KO mice showed significantly reduced E2-responsive ERa downstream genes and exhibited not only morphological but also functional deterioration of the female reproductive $\operatorname{tract}^{58}$. Importin- $\alpha 1$ deficiency may have caused a decrease in the nuclear accumulation of ERa triggered by oestrogen and affected its transcriptional activity.

The subcellular distribution of $3 \times \mathrm{HA}-\mathrm{ER} \alpha$-mNLS dramatically changed to the cytoplasm in the presence of E2 (Fig. 3). Moreover, our data using ERa-mNLS suggest that ERa is exported from the nucleus by (an) other 
A
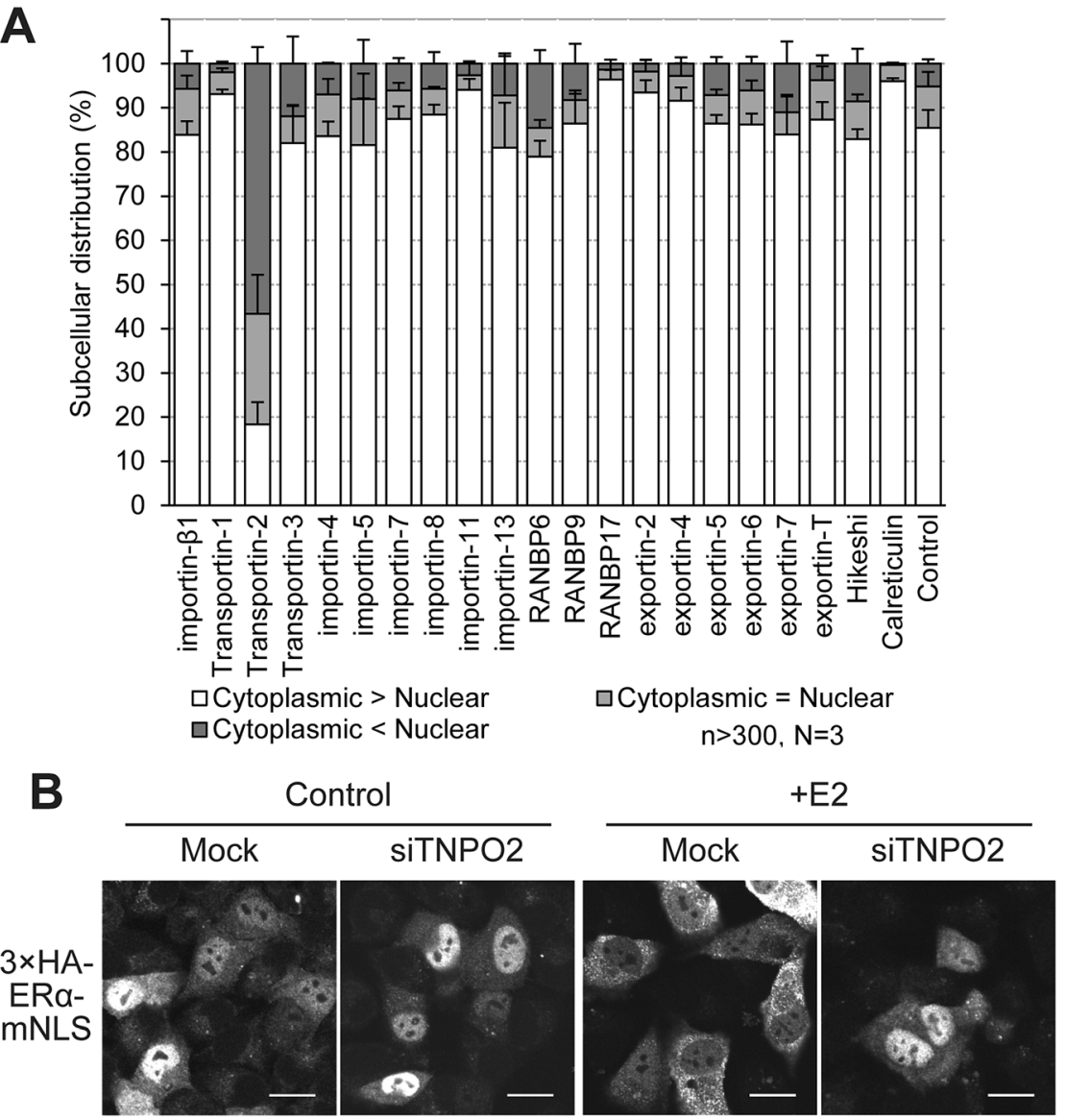

C
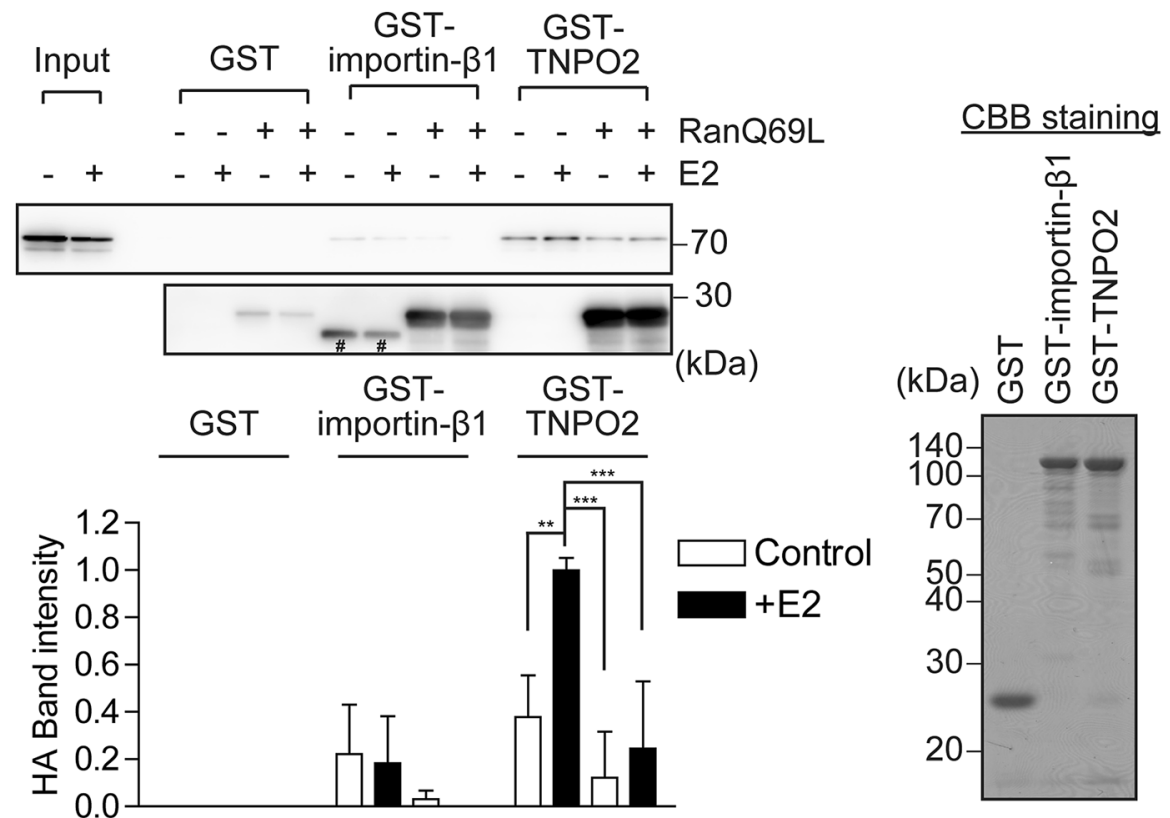
A

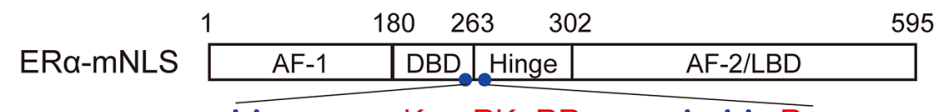

243-AACYEVGMMKGGIRKDRRGGRMLAHAAQRD-272

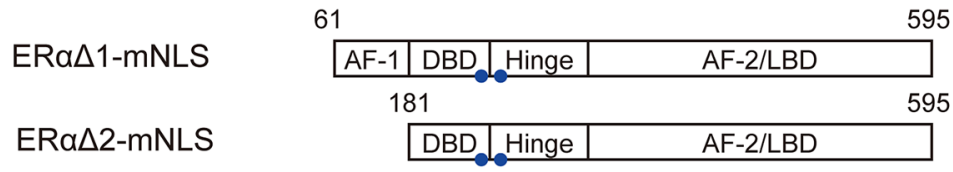

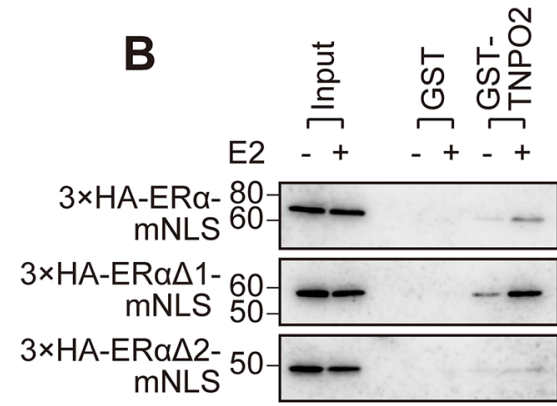

(kDa)
Transportin recognition sequence

$\mathrm{R} / \mathrm{K} / \mathrm{H}-\mathrm{X}_{2-5}-\mathrm{PY}$

MPYS AA

72-VYGQTGLPY-80

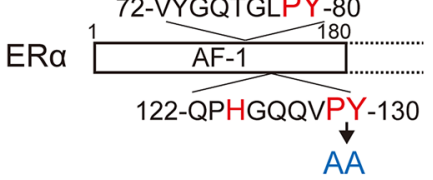

C

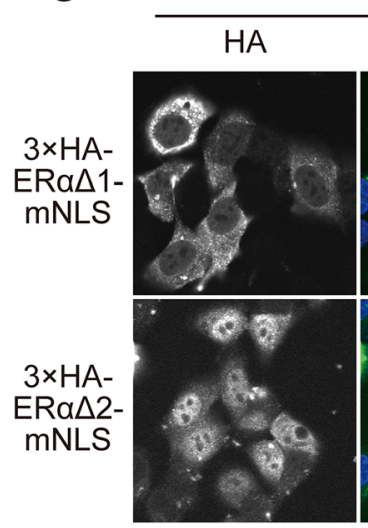

$+\mathrm{E} 2$

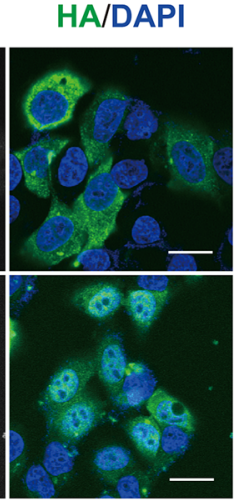

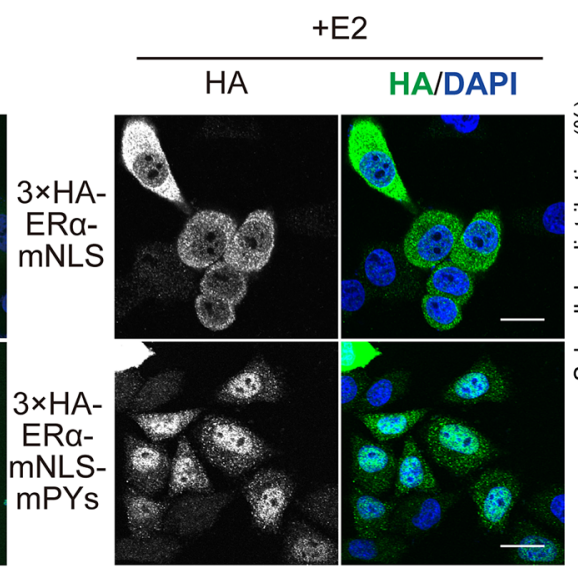

(kDa)

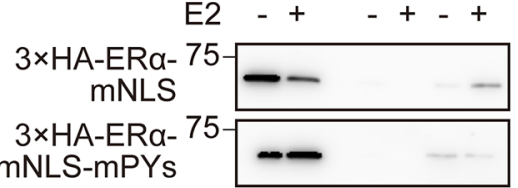

mNLS-mPYs

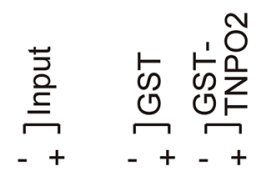

D

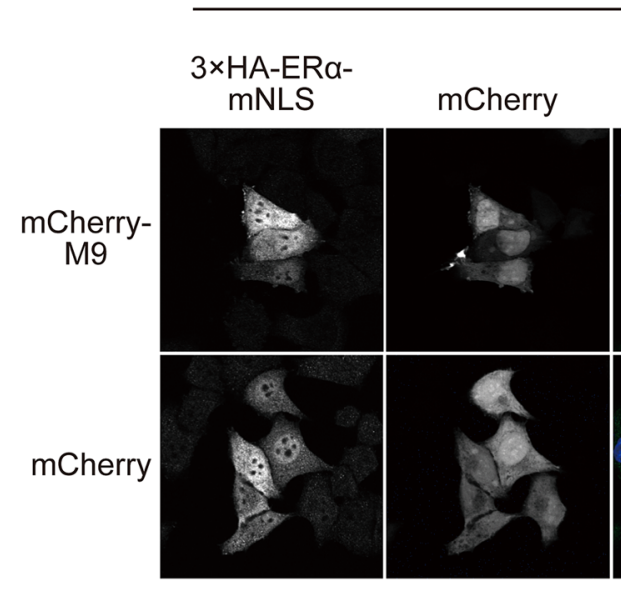

Control 3.HA-ER $\alpha=$
mNLS /DAPI

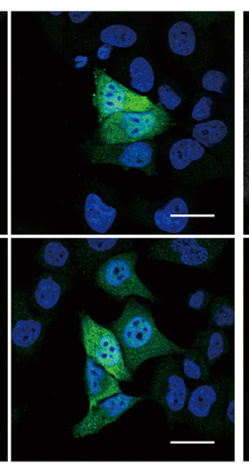

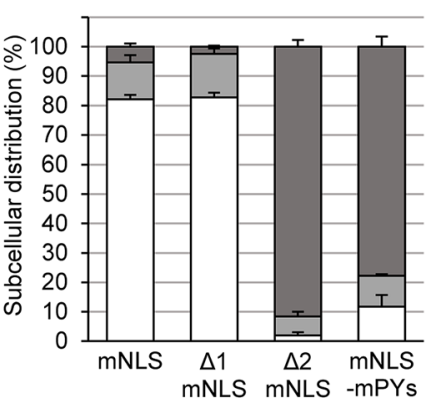

$\square$ Cytoplasmic $<$ Nuclear $\square$ Cytoplasmic $=$ Nuclear $\square$ Cytoplasmic $>$ Nuclear $n>300, N=3$

$+\mathrm{E} 2$

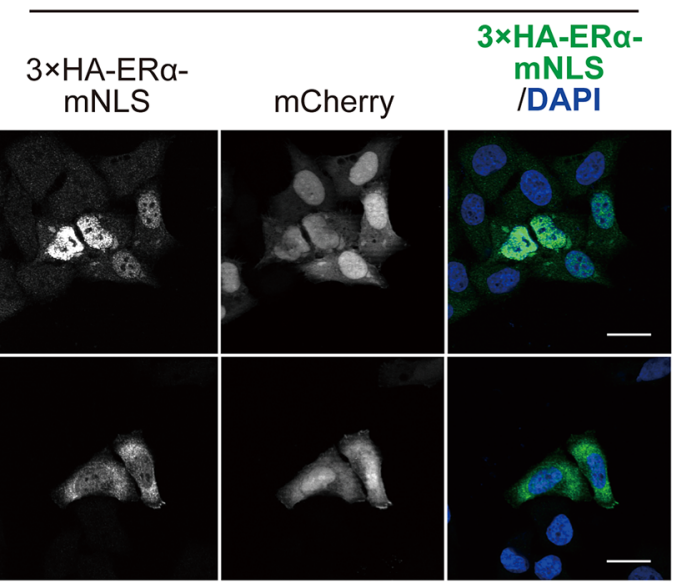


४Figure 5. Transportin-2 binds to ERa via two similar PY-motifs in the AF-1 domain. (A) Schematic representation of the ERa-mNLS deletion mutants and the ERa-mNLS-mPYs. (B) GST pulldown assays were performed with recombinant GST and GST-TNPO2, using HeLa lysates expressing $3 \times$ HA-ERamNLS, $3 \times$ HA-ER $\alpha \Delta 1$-mNLS, or $3 \times$ HA-ER $\alpha \Delta 2$-mNLS (left panel), and $3 \times$ HA-ERa-mNLS or $3 \times$ HA-ER $\alpha$ mNLS-mPYs (right panel). Full-length images of western blots are shown in Supplementary Fig. 12. (C) Immunofluorescence images of $3 \times$ HA-ER $\Delta \Delta 1$-mNLS, $3 \times$ HA-ER $\alpha \Delta 2$-mNLS, $3 \times$ HA-ERa-mNLS, or $3 \times$ HA-ER $\alpha$-mNLS-mPYs in HeLa cells, in the presence of $10 \mathrm{nM} \mathrm{E} 2$ for $3 \mathrm{~h}$. The cells were immunostained for HA (green) and stained with DAPI (blue). Scale bars, $20 \mu \mathrm{m}$. The subcellular distribution (\%) of the $3 \times$ HA-ERa-mNLS mutants was determined from their nuclear, nuclear and cytoplasmic, and cytoplasmic distribution, calculated from $>300$ HA-positive cells. Each data point represents the average of results obtained from three independent experiments and the error bars denote the standard deviation. (D) Immunofluorescence images of HeLa cells co-transfected with $3 \times$ HA-ERa-mNLS and mCherry-M9, in the presence or absence of $10 \mathrm{nM} \mathrm{E2}$, for $2 \mathrm{~h}$. The cells were immunostained for HA (green) and stained with DAPI (blue). Scale bars, $20 \mu \mathrm{m}$.

nuclear export receptor(s), in addition to the previously reported CRM13,31,32 (Supplementary Fig. 3), although we could not identify the receptor(s) in this study. Some nuclear hormone receptors have been reported to be exported from the nucleus via more than one pathway ${ }^{40}$. Thus, ERa is likely to have multiple export pathways.

Endocrine therapy is the primary treatment strategy for ERa-positive breast cancer. However, long-term endocrine therapy (such as tamoxifen and fulvestrant) facilitates translocation of ERa to the cytoplasm and repopulation of cancer cells that have acquired resistance to this treatment ${ }^{59,60}$. Clarifying the ER $\alpha$ shuttling mechanism will lay the groundwork for understanding how ER $\alpha$ trafficking changes in breast cancer before/ after endocrine therapy, and to create a new method that combines ERa transport mechanisms for effective treatment. In summary, our research has demonstrated that TNPO2 controls ER $\alpha$ nucleocytoplasmic shuttling by cytoplasmic retention and inhibition of importin- $\alpha / \beta 1$-dependent nuclear import depending on the stimulation, and thus plays a critical role in the proper regulation of the biological functions of ERa.

\section{Methods}

Plasmid construction. Human ERa, importin- $\alpha 1$, importin- $\alpha 2$, importin- $\alpha 4$, importin- $\beta 1$ and TNPO2 were generated by polymerase chain reaction (PCR) amplification from total RNA from MCF-7 and HeLa cells using appropriate primers (Supplementary Table), and subsequently subcloned into the pENTR vector (Thermo Fisher Scientific, Waltham, MA, USA). ER $\alpha$ mutants and importin- $\alpha \Delta$ IBB were constructed by site-dirlected mutagenesis and by inverse PCR mutagenesis with the KOD-Plus-Neo, Ligation high Ver.2, and T4 Polynucleotide Kinase enzymes (KOD-401, LGK-201, PNK-111, TOYOBO, Osaka, Japan) using primers (Supplementary Table 1). Then, using the Gateway system (Thermo Fisher Scientific), the genes were subcloned into p3 $\times$ FLAG$\mathrm{CMV} \mathrm{DEST}^{61}$, pcDNA3.1/Zeo(+)-EGFP DEST ${ }^{62}$, and pcDNA3.1/Zeo(+) DEST, pGEX-6P-2 DEST, which were generated by a method similar to ${ }^{62,63}$ using pcDNA3.1/Zeo(+) (Thermo Fisher Scientific), pGEX-6P-2 (Cytiva, Piscataway, NJ, USA) and the Reading Frame Cassette of the Gateway Conversion System (Thermo Fisher Scientific). pCold II Ran Q69L was constructed by inserting the human Ran Q69L mutant into pCold II DNA (Takara Bio Inc., Shiga, Japan).

Cell culture. HeLa and MCF-7 cells were cultured in Dulbecco's modified Eagle's medium (D-MEM; 04429765, FUJIFILM Wako Pure Chemical Corporation, Osaka, Japan) supplemented with 10\% foetal bovine serum (FBS). The cells were maintained in a $37^{\circ} \mathrm{C}$ incubator with $5 \% \mathrm{CO} 2$-humidified air.

For E2 treatment, cells were maintained in 5\% Charcoal/Dextran-treated FBS (Thermo Fisher Scientific) in phenol red-free D-MEM (044-32955, FUJIFILM Wako Pure Chemical Corporation) for 2 days, and then serumfree media before experimentation.

In vitro transport assay. An in vitro transport assay was performed as described previously ${ }^{65,66}$. Briefly, HeLa cells were grown on multiwell plates (TF2404; Matsunami Glass Ind., Ltd., Osaka, Japan) for 2 days. After washing with ice-cold transport buffer (TB; $20 \mathrm{mM}$ HEPES [pH 7.3], $110 \mathrm{mM}$ potassium acetate, $2 \mathrm{mM}$ magnesium acetate, $5 \mathrm{mM}$ sodium acetate, $0.5 \mathrm{mM}$ EGTA, $2 \mathrm{mM} \mathrm{DTT}, 1 \mu \mathrm{g} / \mathrm{mL}$ aprotinin, $1 \mu \mathrm{g} / \mathrm{mL}$ leupeptin, and $1 \mu \mathrm{g} / \mathrm{mL}$ pepstatin), the cells were permeabilised with $20 \mu \mathrm{g} / \mathrm{mL}$ Digitonin, High Purity (300410, Merck Millipore, Burlington, MA, USA) in TB on ice for $5 \mathrm{~min}$. Cells were then washed and immersed in ice-cold TB for $10 \mathrm{~min}$. Preincubated $400 \mathrm{nM}$ GFP-cargo-substrate, $600 \mathrm{nM}$ importin- $\alpha, 400 \mathrm{nM}$ importin- $\beta 1$ and $4 \mu \mathrm{M}$ RanGDP were mixed with $500 \mu \mathrm{M}$ GTP and an ATP-regeneration system ( $3.3 \mu \mathrm{M}$ ATP, $15 \mu \mathrm{M}$ phosphocreatine, and $60 \mathrm{U} / \mathrm{mL}$ creatine phosphokinase) in TB containing 1\% BSA. After applying the mixture, the digitoninpermeabilized cells were incubated at $30^{\circ} \mathrm{C}$ for $30 \mathrm{~min}$. Finally, the cells were rinsed with ice-cold TB and fixed with $3.7 \%$ formaldehyde in TB for $15 \mathrm{~min}$. The cells were then stained with DAPI.

Transient transfection. Transfections were performed using Lipofectamine 2000 Transfection Reagent (Thermo Fisher Scientific) and ScreenFect A plus (FUJIFILM Wako Pure Chemical Corporation) according to the manufacturer's instructions. siRNA duplexes were reverse transfected into HeLa and MCF-7 cells using Lipofectamine RNAiMAX Transfection Reagent (Thermo Fisher Scientific) as recommended by the manufacturer. 
A

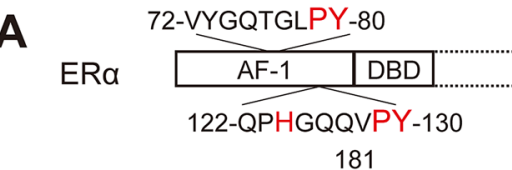

$E R \alpha \Delta 2$

B

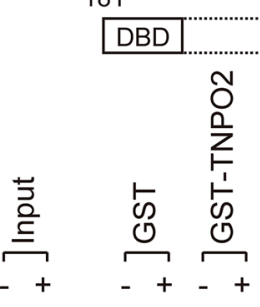

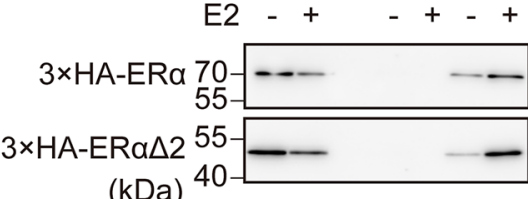

(kDa) 40

D

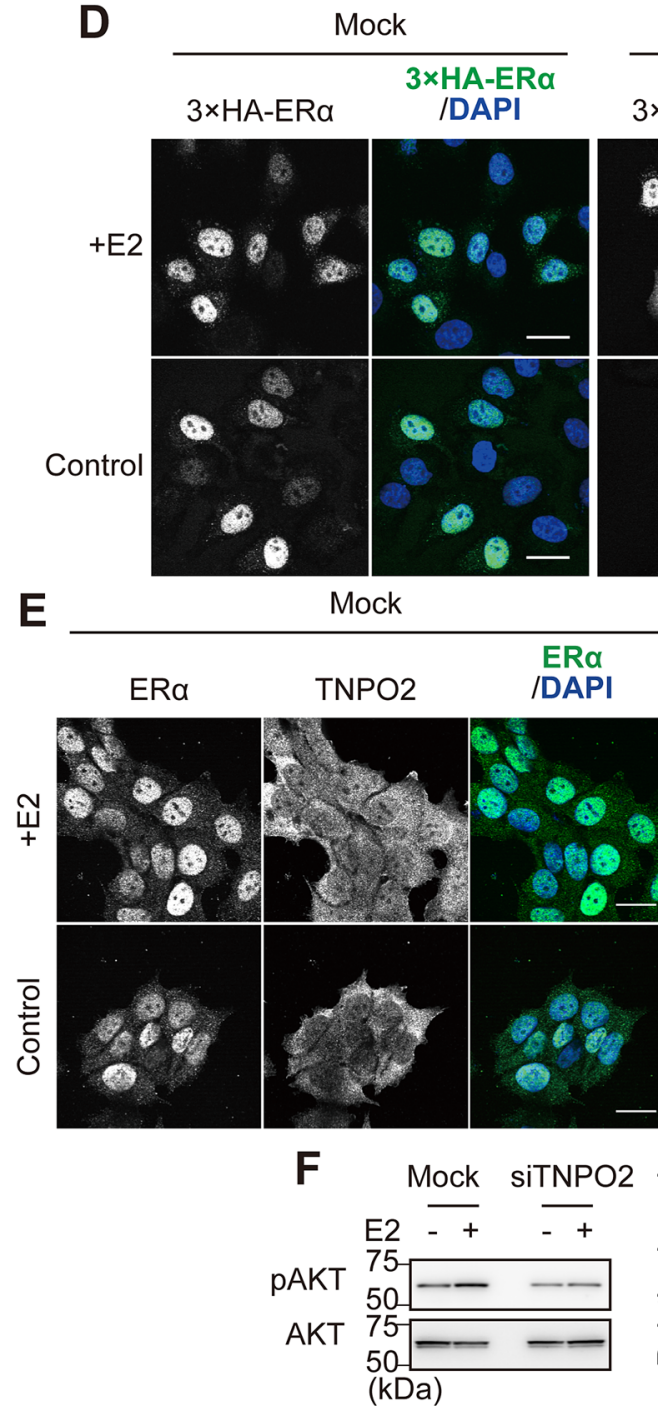

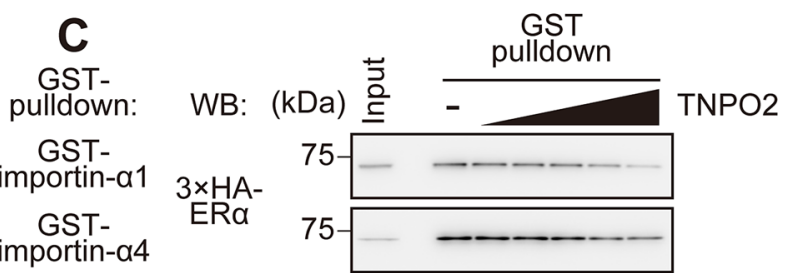

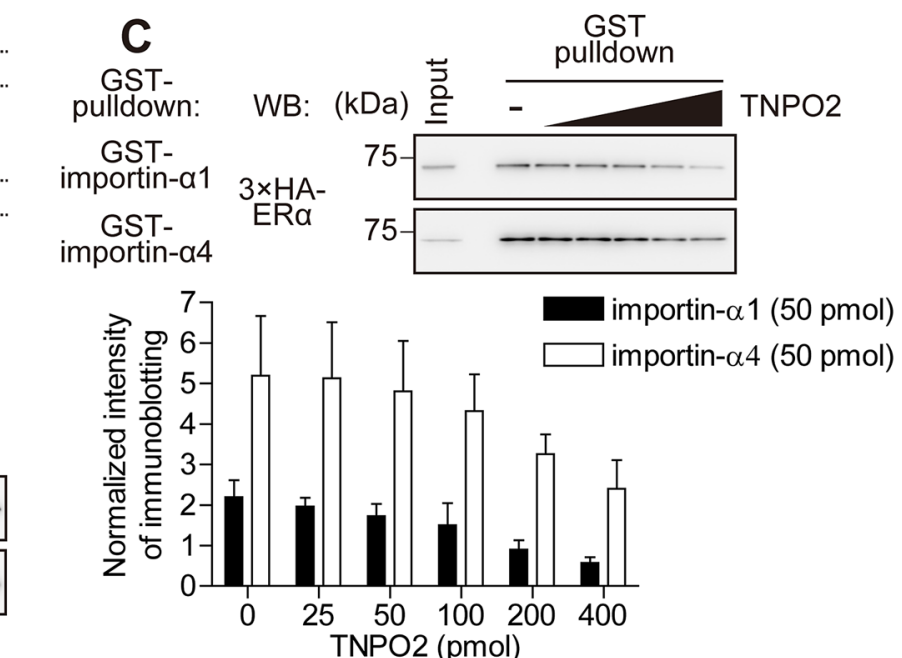

$3 \times$ Flag-TNPO2
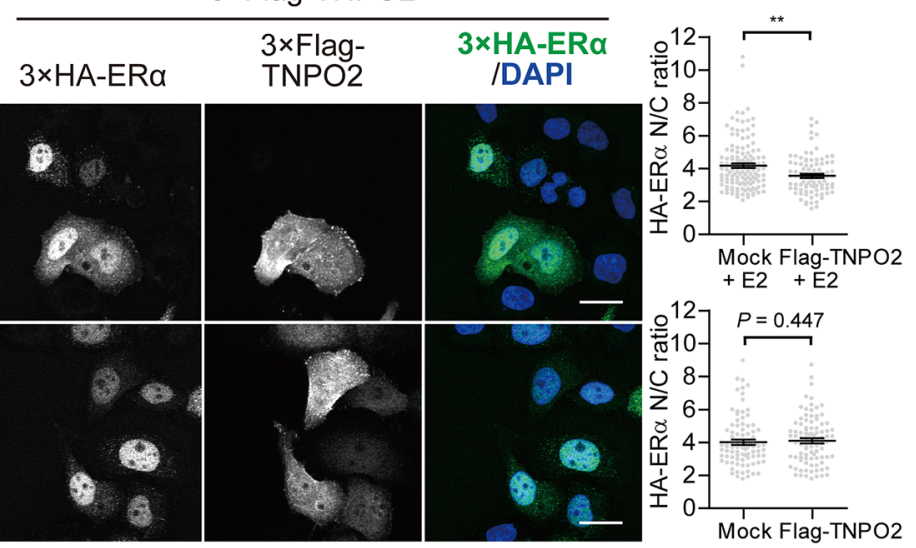

siTNPO2

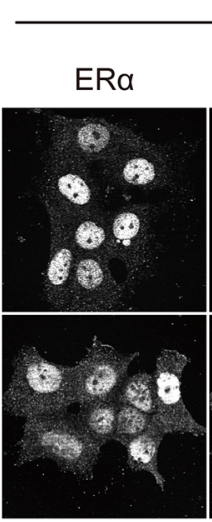

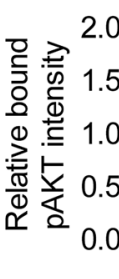

TNPO2
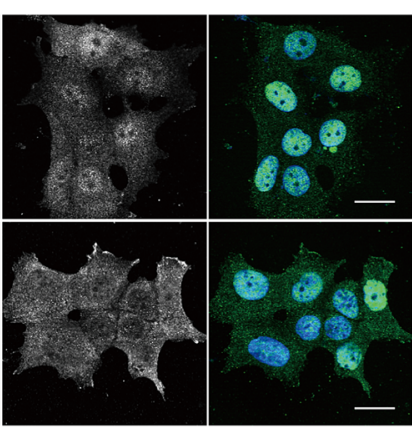

$\square$ Control

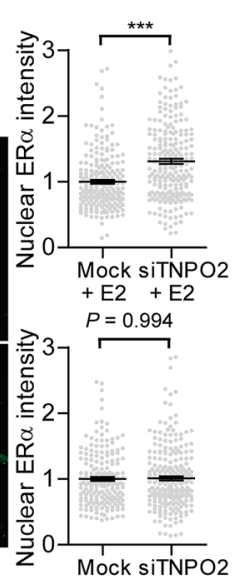


4Figure 6. Transportin-2 and importin-a competitively binds to the basic region of the NLS of ERa for modulating its function. (A) Schematic representation of the ERa mutants. (B) GST pulldown assays were performed with recombinant GST and GST-TNPO2, using HeLa lysates expressing $3 \times$ HA-ERa or $3 \times$ HA-ER $\alpha \Delta 2$. (C) Competitive binding of importin- $\alpha 1$ or importin- $\alpha 4$ and TNPO2 to ER $\alpha$. GST-importin- $\alpha 1$ or GST-importin- $\alpha 4$ were immobilised on glutathione Sepharose beads and incubated with HeLa lysates expressing $3 \times \mathrm{HA}-\mathrm{ER} \alpha$, in the presence of $10 \mathrm{nM}$ E2. The beads were washed and incubated with different amounts of TNPO2. The bound fraction was analysed by immunoblotting for HA. The quantities of GSTimportin- $\alpha 1$, GST-importin- $\alpha 4$, and $3 \times$ HA-ER a complexes are represented graphically. Intensity of $3 \times$ HA-ER $\alpha$ was normalised to the intensity of the input. Each data point represents the average of results obtained from three independent experiments and the error bars denote the standard deviation. (D) Immunofluorescence images of HeLa cells co-transfected with $3 \times$ HA-ER $\alpha$ and $3 \times$ Flag-TNPO2, in the presence or absence of $10 \mathrm{nM}$ E2, for $10 \mathrm{~min}$. The cells were immunostained for HA (green) and Flag, and stained with DAPI (blue). Scale bars, $20 \mu \mathrm{m}$. The graphs depict Nuclear/Cytoplasm (N/C) ratio of $3 \times$ HA-ERa staining intensity calculated from the average of at least 90 cells and the error bars denote the corresponding standard error. ${ }^{\star *} P<0.01$ determined by the Mann-Whitney test through comparison with the mock samples, in the presence or absence of E2. (E) Immunofluorescence images of endogenous ERa and TNPO2 in MCF-7 cells transfected with or without TNPO2-specific siRNAs, in the presence of $10 \mathrm{nM} \mathrm{E2}$, for $10 \mathrm{~min}$. The cells were immunostained for ERa (green) and TNPO2 (red). Scale bars, $20 \mu \mathrm{m}$. The graphs depict the intranuclear ERa staining intensity, averaged from at least 180 cells and the error bars denote the average standard errors. ${ }^{\star *}{ }^{*} P<0.001$, the MannWhitney test, compared with the mocks, in the presence or absence of E2. (F) TNPO2 knockdown inhibited the E2-dependent AKT activation. MCF-7 cells were transfected with TNPO2-specific siRNAs, and treated with $10 \mathrm{nM}$ E2 for $15 \mathrm{~min}$. The cells were lysed and subjected to SDS-PAGE. Western blotting was performed using anti-phosphorylated-AKT and anti-AKT antibodies. The pAKT/AKT ratio in the absence of E2 was set to 1. Each data point represents the average of data from five independent experiments and the error bars denote the standard deviation. ${ }^{*} P<0.01$, the Paired ratio t-test, compared with the control. Full-length images of western blots are shown in Supplementary Fig. 13.

Antibodies. ERa Antibody (F-10) (sc-8002, Santa Cruz Biotechnology, Dallas, TX, USA), Anti-HA-tag mAb (M180-3, MBL, Nagoya, Japan), Monoclonal ANTI-FLAG M2 antibody produced in mouse (F1804, Merck Millipore), Ran BP-1 Antibody (M-45) (sc-28576, Santa Cruz Biotechnology), Actin Antibody (C-11) (sc-1615, Santa Cruz Biotechnology), Purified Mouse Anti-Karyopherin $\beta$ (610559, BD Transduction Laboratories, San Jose, CA, USA), Purified Mouse anti-Transportin (558660, BD Transduction Laboratories), TNPO2 Polyclonal antibody (17831-1-AP, ProteinTech, Chicago, IL, USA), IPO4 Rabbit pAb (A15600, ABclonal, Cambridge, MA, USA), Anti-Importin 7 antibody (ab99273, abcam, Cambridge, MA, USA), Anti-Cellular Apoptosis Susceptibility/CSE1L antibody (ab96755, abcam), Purified Mouse Anti-Ran (610340, BD Transduction Laboratories), Phospho-Akt (Ser473) (D9E) XP Rabbit mAb (4060, Cell Signaling Technology, Danvers, MA, USA), Akt (pan) (C67E7) Rabbit mAb (4691, Cell Signaling Technology) were used.

siRNA oligos. Importin- $\beta$ family, Hikeshi and CALR Silencer Select (Pre-designed) siRNAs were synthesized by Thermo Fisher Scientific: importin- $\beta 1$ (ID: s7917), TNPO1 (ID:s7933), TNPO2 (ID:s26881), TNPO3 (ID:s24032), importin-4 ID:s36153), importin-5 (ID:s7935), importin-7 (ID:s20640), importin-8 (ID:s20637), importin-11 (ID:s27652), importin-13 (ID:s18609), RanBP6 (ID:s25641), RanBP9 (ID:s19529), exportin-7 (RanBP16, ID:s22894), exportin-2 (CSE1L, ID:s3588), exportin-4 (ID:s34638), exportin-5 (ID:s33190), exportin-6 (ID: s23302), exportin-T (ID:s22232), RanBP17 (ID:s35075), Hikeshi (ID:s28222), Calreticulin (ID:s114).

Expression and purification of recombinant proteins. GST-fusion proteins were expressed in Escherichia coli strain BL21 and RosettaBlue (Merck Millipore), and purified with Glutathione Sepharose 4B (17075601, Cytiva). GST cleavage was performed using Turbo3C Protease (Accelagen, San Diego, CA, USA). Hexahistidine $(6 \times$ His)-RanQ69L was expressed in BL21 and purified with TALON Metal Affinity Resin (Takara Bio Inc.). The GTP-bound RanQ69L was purified as described previously ${ }^{64}$.

GST pulldown assay. At $24 \mathrm{~h}$ after transfection, HeLa cells were washed with cold PBS. The cells were lysed with lysis buffer (20 mM HEPES/NaOH [pH 7.3], $150 \mathrm{mM} \mathrm{NaCl}, 5 \mathrm{mM} \mathrm{MgCl}, 0.05 \%$ Tween-20, $1 \mu \mathrm{g} / \mathrm{mL}$ each of aprotinin, leupeptin, and pepstatin A). These lysates were centrifuged at 20,400 $\mathrm{g}$ for $30 \mathrm{~min}$, and the supernatants were collected and quantified using a DC Protein Assay kit (Bio-Rad Laboratories, Inc., Hercules, CA, USA). GST pulldown assays were performed by mixing cell lysates with Glutathione Sepharose $4 \mathrm{~B}$ charged with 50 pmol GST fusion proteins with or without $2 \mu \mathrm{M} 6 \times$ His-RanQ69L. The beads were washed with lysis buffer and resuspended in Laemmli sample buffer, and subsequently analysed by SDS-PAGE and western blotting. Quantification of western blot band signals was performed with CS Analyzer software and statistical analysis was performed using GraphPad Prism.

Immunofluorescence. HeLa cells and MCF-7 cells grown on glass cover slides in a 12-well culture plates were fixed with formaldehyde for $10 \mathrm{~min}$ at room temperature, permeabilized with PBS containing $0.2 \%$ TritonX-100 and washed with PBS. After blocking with blocking buffer ( $137 \mathrm{mM} \mathrm{NaCl}, 2.7 \mathrm{mM} \mathrm{KCl}, \mathrm{Na}_{2} \mathrm{HPO}_{4}$, $\mathrm{KH}_{2} \mathrm{PO}_{4}, 1 \% \mathrm{BSA}, 2 \%$ horse serum, $0.1 \%$ gelatin, $0.1 \%$ Triton $\mathrm{X}-100,0.05 \%$ Tween $20,0.05 \%$ sodium azide), the cells were incubated with primary antibodies. After washing with PBS, Alexa Fluor Plus 488- and 555-conjugated secondary antibodies (Thermo Fisher Scientific) were used. Nuclei were stained with $0.1 \mu \mathrm{g} / \mathrm{mL}$ DAPI 


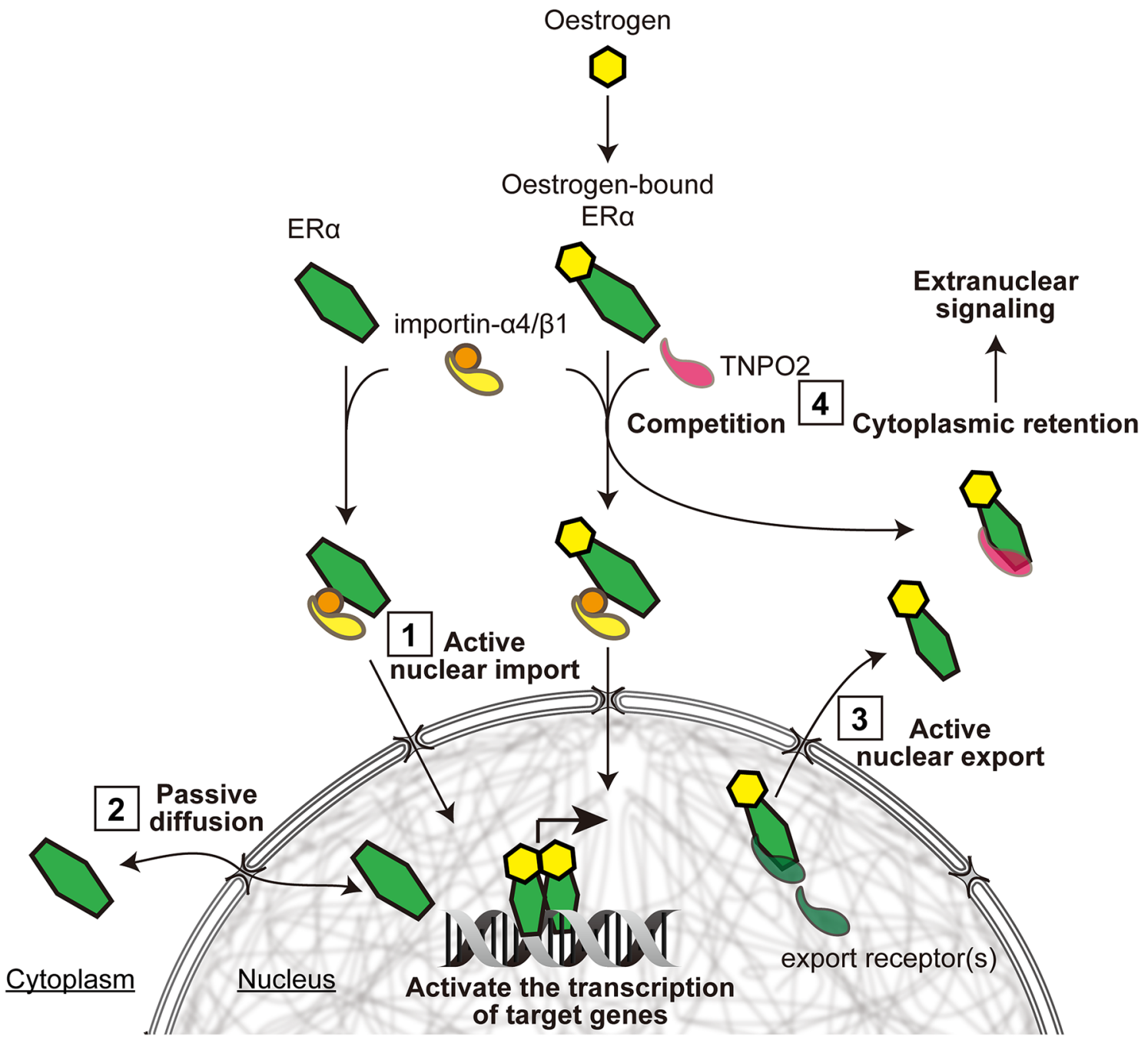

Figure 7. A model for the nucleocytoplasmic shuttling of ERa, regulated by the importin family. Following cytoplasmic translation, ER $\alpha$ translocates into the nucleus by active transport mediated by importin- $\alpha 4 / \beta$ (1). ERa can also shuttle between the nucleus and cytoplasm by passive diffusion (2). Simultaneously, nuclear export receptor(s) export ER $\alpha$ from the nucleus (3). In the cytoplasm, TNPO2 shields the NLS from importin- $\alpha$ and increases the cytoplasmic retention of ERa in an E2-dependent manner (4).

(Dojindo, Kumamoto, Japan). Fluorescence was observed using an Olympus FV-1200 confocal microscope (Olympus, Tokyo, Japan). Quantification of nuclear signal was performed with ImageJ software, and statistical analysis was performed in GraphPad Prism.

Quantitative RT-PCR. Real-time PCR reactions were carried out using an ABI PRISM 7900 (Thermo Fisher Scientific). The amplicons were designed to amplify fragments of $>150$-bp (Supplementary Table 2). A One Step SYBR PrimeScript RT-PCR Kit II (Takara Bio Inc.) was used for the one-step RT-PCR reactions containing total RNA from siRNA-transfected HeLa cells as a template. According to the manufacturer's protocol, reverse transcription was conducted at $42{ }^{\circ} \mathrm{C}$ for $5 \mathrm{~min}$ and then $95^{\circ} \mathrm{C}$ for $10 \mathrm{~s}$, followed by an initial activation at $95^{\circ} \mathrm{C}$ for $5 \mathrm{~s}$ and $60^{\circ} \mathrm{C}$ for $30 \mathrm{~s}$ for a total of 40 cycles.

\section{Data availability}

The datasets generated and/or analysed during the current study are available from the corresponding author upon reasonable request.

Received: 29 June 2020; Accepted: 16 October 2020

Published online: 29 October 2020

\section{References}

1. Levin, E. R. Integration of the extranuclear and nuclear actions of estrogen. Mol. Endocrinol. 19, 1951-1959. https://doi.org/10.1210/ me.2004-0390 (2005). 
2. Vrtacnik, P., Ostanek, B., Mencej-Bedrac, S. \& Marc, J. The many faces of estrogen signaling. Biochem. Med. 24, 329-342. https:// doi.org/10.11613/Bm.2014.035 (2014).

3. Maruvada, P., Baumann, C. T., Hager, G. L. \& Yen, P. M. Dynamic shuttling and intranuclear mobility of nuclear hormone receptors. J. Biol. Chem. 278, 12425-12432. https://doi.org/10.1074/jbc.M202752200 (2003).

4. Kocanova, S., Mazaheri, M., Caze-Subra, S. \& Bystricky, K. Ligands specify estrogen receptor alpha nuclear localization and degradation. Bmc Cell Biol. 11, 98. https://doi.org/10.1186/1471-2121-11-98 (2010).

5. Razandi, M., Pedram, A., Greene, G. L. \& Levin, E. R. Cell membrane and nuclear estrogen receptors (ERs) originate from a single transcript: studies of ER alpha and ER beta expressed in Chinese hamster ovary cells. Mol. Endocrinol. 13, 307-319. https://doi. org/10.1210/Me.13.2.307 (1999).

6. Acconcia, F. et al. Palmitoylation-dependent estrogen receptor alpha membrane localization: regulation by 17 beta-estradiol. Mol. Biol. Cell 16, 231-237. https://doi.org/10.1091/mbc.e04-07-0547 (2005).

7. Morley, P., Whitfield, J. F., Vanderhyden, B. C., Tsang, B. K. \& Schwartz, J. L. A new, nongenomic estrogen action: the rapid release of intracellular calcium. Endocrinology 131, 1305-1312. https://doi.org/10.1210/endo.131.3.1505465 (1992).

8. Castoria, G. et al. PI3-kinase in concert with Src promotes the S-phase entry of oestradiol-stimulated MCF-7 cells. Embo J. 20, 6050-6059. https://doi.org/10.1093/emboj/20.21.6050 (2001).

9. Kahlert, S. et al. Estrogen receptor alpha rapidly activates the IGF-1 receptor pathway. J. Biol. Chem. 275, 18447-18453. https:// doi.org/10.1074/jbc.M910345199 (2000).

10. Chung, Y. L., Sheu, M. L., Yang, S. C., Lin, C. H. \& Yen, S. H. Resistance to tamoxifen-induced apoptosis is associated with direct interaction between Her2/neu and cell membrane estrogen receptor in breast cancer. Int. J. Cancer 97, 306-312. https://doi. org/10.1002/ijc.1614 (2002).

11. Razandi, M., Pedram, A., Park, S. T. \& Levin, E. R. Proximal events in signaling by plasma membrane estrogen receptors. J. Biol. Chem. 278, 2701-2712. https://doi.org/10.1074/jbc.M205692200 (2003).

12. Pedram, A. et al. Developmental phenotype of a membrane only estrogen receptor alpha(MOER) mouse. J. Biol. Chem. 284, 3488-3495. https://doi.org/10.1074/jbc.M806249200 (2009).

13. Pedram, A., Razandi, M., Lewis, M., Hammes, S. \& Levin, E. R. Membrane-localized estrogen receptor alpha is required for normal organ development and function. Dev. Cell. 29, 482-490. https://doi.org/10.1016/j.devcel.2014.04.016 (2014).

14. Gustafsson, K. L. et al. The role of membrane ERalpha signaling in bone and other major estrogen responsive tissues. Sci. Rep. 6, 29473. https://doi.org/10.1038/srep29473 (2016).

15. Nanjappa, M. K. et al. Membrane-localized estrogen receptor 1 is required for normal male reproductive development and function in mice. Endocrinology 157, 2909-2919. https://doi.org/10.1210/en.2016-1085 (2016).

16. Pedram, A., Razandi, M., Blumberg, B. \& Levin, E. R. Membrane and nuclear estrogen receptor alpha collaborate to suppress adipogenesis but not triglyceride content. FASEB J. 30, 230-240. https://doi.org/10.1096/ff.15-274878 (2016).

17. Allard, C. et al. Loss of nuclear and membrane estrogen receptor-alpha differentially impairs insulin secretion and action in male and female mice. Diabetes 68, 490-501. https://doi.org/10.2337/db18-0293 (2019).

18. Burns, K. A., Li, Y., Arao, Y., Petrovich, R. M. \& Korach, K. S. Selective mutations in estrogen receptor alpha D-domain alters nuclear translocation and non-estrogen response element gene regulatory mechanisms. J. Biol. Chem. https://doi.org/10.1074/jbc. M110.187773 (2011)

19. Stefkovich, M. L., Arao, Y., Hamilton, K. J. \& Korach, K. S. Experimental models models for evaluating non-genomic estrogen signaling. Steroids 133, 34-37. https://doi.org/10.1016/j.steroids.2017.11.001 (2018).

20. Kimura, M. \& Imamoto, N. Biological significance of the importin-beta family-dependent nucleocytoplasmic transport pathways. Traffic 15, 727-748. https://doi.org/10.1111/tra.12174 (2014).

21. Oka, M. \& Yoneda, Y. Importin alpha: functions as a nuclear transport factor and beyond. Proc. Jpn. Acad. B 94, 259-274. https:// doi.org/10.2183/pjab.94.018 (2018).

22. Savory, J. G. A. et al. Discrimination between NL1- and NL2-mediated nuclear localization of the glucocorticoid receptor. Mol. Cell. Biol. 19, 1025-1037 (1999).

23. Freedman, N. D. \& Yamamoto, K. R. Importin 7 and importin alpha/Importin beta are nuclear import receptors for the glucocorticoid receptor. Mol. Biol. Cell. 15, 2276-2286. https://doi.org/10.1091/mbc.E03-11-0839 (2004).

24. Tao, T., Lan, J., Lukacs, G. L., Hache, R. J. G. \& Kaplan, F. Importin 13 regulates nuclear import of the glucocorticoid receptor in airway epithelial cells. Am. J. Resp. Cell Mol. 35, 668-680. https://doi.org/10.1165/rcmb.2006-0073OC (2006).

25. Tanaka, M., Nishi, M., Morimoto, M., Sugimoto, T. \& Kawata, M. Imaging analysis of mineralocorticoid receptor and importins in single living cells by using GFP color variants. Cell Tissue Res. 320, 447-453. https://doi.org/10.1007/s00441-004-0984-5 (2005).

26. Cutress, M. L., Whitaker, H. C., Mills, I. G., Stewart, M. \& Neal, D. E. Structural basis for the nuclear import of the human androgen receptor. J. Cell Sci. 121, 957-968. https://doi.org/10.1242/jcs.022103 (2008).

27. Schutz, S. V., Cronauer, M. V. \& Rinnab, L. Inhibition of glycogen synthase kinase-3 beta promotes nuclear export of the androgen receptor through a CRM1-dependent mechanism in prostate cancer cell lines. J. Cell Biochem. 109, 1192-1200. https://doi. org $/ 10.1002 /$ jcb. 22500 (2010).

28. Shank, L. C. et al. Activation of the DNA-dependent protein kinase stimulates nuclear export of the androgen receptor in vitro. J. Biol. Chem. 283, 10568-10580. https://doi.org/10.1074/jbc.M800810200 (2008).

29. Grespin, M. E. et al. Thyroid hormone receptor alpha 1 follows a cooperative CRM1/calreticulin-mediated nuclear export pathway. J. Biol. Chem. 283, 25576-25588. https://doi.org/10.1074/jbc.M710482200 (2008).

30. Subramanian, K. S. et al. Multiple exportins influence thyroid hormone receptor localization. Mol. Cell Endocrinol. 411, 86-96. https://doi.org/10.1016/j.mce.2015.04.014 (2015).

31. Nonclercq, D. et al. Effect of nuclear export inhibition on estrogen receptor regulation in breast cancer cells. J. Mol. Endocrinol. 39, 105-118. https://doi.org/10.1677/Jme-07-0040 (2007).

32. Castoria, G. et al. Tyrosine phosphorylation of estradiol receptor by Src regulates its hormone-dependent nuclear export and cell cycle progression in breast cancer cells. Oncogene 31, 4868-4877. https://doi.org/10.1038/onc.2011.642 (2012).

33. Picard, D., Kumar, V., Chambon, P. \& Yamamoto, K. R. Signal transduction by steroid hormones: nuclear localization is differentially regulated in estrogen and glucocorticoid receptors. Cell Regul. 1, 291-299 (1990).

34. Ylikomi, T., Bocquel, M. T., Berry, M., Gronemeyer, H. \& Chambon, P. Cooperation of proto-signals for nuclear accumulation of estrogen and progesterone receptors. Embo J. 11, 3681-3694 (1992).

35. Wang, R. W. \& Brattain, M. G. The maximal size of protein to diffuse through the nuclear pore is larger than $60 \mathrm{kDa}$. FEBS Lett. 581, 3164-3170. https://doi.org/10.1016/j.febslet.2007.05.082 (2007).

36. Plafker, K. \& Macara, I. G. Facilitated nucleocytoplasmic shuttling of the Ran binding protein RanBP1. Mol. Cell. Biol. 20, 35103521. https://doi.org/10.1128/Mcb.20.10.3510-3521.2000 (2000).

37. Malnou, C. E. et al. Heterodimerization with jun family members regulates c-fos nucleocytoplasmic traffic. J. Biol. Chem. 282, 31046-31059. https://doi.org/10.1074/jbc.M702833200 (2007).

38. Kudo, N. et al. Leptomycin B inhibition of signal-mediated nuclear export by direct binding to CRM1. Exp. Cell. Res. 242, 540-547. https://doi.org/10.1006/excr.1998.4136 (1998).

39. Holaska, J. M., Black, B. E., Rastinejad, F. \& Paschal, B. M. Ca2+-dependent nuclear export mediated by calreticulin. Mol. Cell. Biol. 22, 6286-6297. https://doi.org/10.1128/Mcb.22.17.6286-6297.2002 (2002). 
40. Tecalco-Cruz, A. C. Molecular pathways involved in the transport of nuclear receptors from the nucleus to cytoplasm. J. Steroid. Biochem. 178, 36-44. https://doi.org/10.1016/j.jsbmb.2017.10.020 (2018).

41. Kose, S., Furuta, M. \& Imamoto, N. Hikeshi, a nuclear import carrier for Hsp70s, protects cells from heat shock-induced nuclear damage. Cell 149, 578-589. https://doi.org/10.1016/j.cell.2012.02.058 (2012).

42. Fornerod, M., Ohno, M., Yoshida, M. \& Mattaj, I. W. CRM1 is an export receptor for leucine-rich nuclear export signals. Cell 90, 1051-1060. https://doi.org/10.1016/S0092-8674(00)80371-2 (1997).

43. Kutay, U., Bischoff, F. R., Kostka, S., Kraft, R. \& Gorlich, D. Export of importin alpha from the nucleus is mediated by a specific nuclear transport factor. Cell 90, 1061-1071. https://doi.org/10.1016/S0092-8674(00)80372-4 (1997).

44. Mingot, J. M., Kostka, S., Kraft, R., Hartmann, E. \& Gorlich, D. Importin 13: a novel mediator of nuclear import and export. Embo J. 20, 3685-3694. https://doi.org/10.1093/emboj/20.14.3685 (2001).

45. Twyffels, L., Gueydan, C. \& Kruys, V. Transportin-1 and Transportin-2: protein nuclear import and beyond. FEBS Lett. 588, 1857-1868. https://doi.org/10.1016/j.febslet.2014.04.023 (2014).

46. Lee, B. J. et al. Rules for nuclear localization sequence recognition by karyopherin beta 2. Cell 126, 543-558. https://doi. org/10.1016/j.cell.2006.05.049 (2006).

47. Izaurralde, E. et al. A role for the M9 transport signal of hnRNP A1 in mRNA nuclear export. J. Cell. Biol. 137, 27-35. https://doi. org/10.1083/Jcb.137.1.27 (1997).

48. Hindley, C. E., Lawrence, F. J. \& Matthews, D. A. A role for transportin in the nuclear import of adenovirus core proteins and DNA. Traffic 8, 1313-1322. https://doi.org/10.1111/j.1600-0854.2007.00618.x (2007).

49. Sekimoto, T., Miyamoto, Y., Arai, S. \& Yoneda, Y. Importin alpha protein acts as a negative regulator for snail protein nuclear import. J. Biol. Chem. 286, 15126-15131. https://doi.org/10.1074/jbc.M110.213579 (2011).

50. Yasuhara, N. et al. Importin alpha subtypes determine differential transcription factor localization in embryonic stem cells maintenance. Dev. Cell. 26, 123-135. https://doi.org/10.1016/j.devcel.2013.06.022 (2013).

51. Ni, L. et al. Androgen induces a switch from cytoplasmic retention to nuclear import of the androgen receptor. Mol. Cell. Biol. 33, 4766-4778. https://doi.org/10.1128/Mcb.00647-13 (2013).

52. Kimoto, C. et al. Functional characterization of importin alpha 8 as a classical nuclear localization signal receptor. BBA-Mol. Cell Res. 2676-2683, 2015. https://doi.org/10.1016/j.bbamcr.2015.07.017 (1853).

53. Van Dusen, C. M., Yee, L., McNally, L. M. \& McNally, M. T. A Glycine-rich domain of hnRNP H/f promotes nucleocytoplasmic shuttling and nuclear import through an interaction with transportin 1. Mol. Cell Biol. 30, 2552-2562. https://doi.org/10.1128/ Mcb.00230-09 (2010).

54. Springhower, C. E., Rosen, M. K. \& Chook, Y. M. Karyopherins and condensates. Curr. Opin. Cell Biol. 64, 112-123. https://doi. org/10.1016/j.ceb.2020.04.003 (2020).

55. Walde, S. et al. The nucleoporin Nup358/RanBP2 promotes nuclear import in a cargo- and transport receptor-specific manner. Traffic 13, 218-233. https://doi.org/10.1111/j.1600-0854.2011.01302.x (2012).

56. Song, R. X. et al. The role of Shc and insulin-like growth factor 1 receptor in mediating the translocation of estrogen receptor alpha to the plasma membrane. Proc. Natl. Acad. Sci. USA 101, 2076-2081. https://doi.org/10.1073/pnas.0308334100 (2004).

57. Jakel, S., Mingot, J. M., Schwarzmaier, P., Hartmann, E. \& Gorlich, D. Importins fulfil a dual function as nuclear import receptors and cytoplasmic chaperones for exposed basic domains. Embo J. 21, 377-386. https://doi.org/10.1093/emboj/21.3.377 (2002).

58. Moriyama, T. et al. Targeted disruption of one of the importin alpha family members leads to female functional incompetence in delivery. FEBS J. 278, 1561-1572. https://doi.org/10.1111/j.1742-4658.2011.08079.x (2011).

59. Fan, P., Wang, J. P., Santen, R. J. \& Yue, W. Long-term treatment with tamoxifen facilitates translocation of estrogen receptor alpha out of the nucleus and enhances its interaction with EGFR in MCF-7 breast cancer cells. Cancer Res. 67, 1352-1360. https://doi. org/10.1158/0008-5472.CAN-06-1020 (2007).

60. Song, R. X. D. et al. Estrogen utilization of IGF-1-R and EGF-R to signal in breast cancer cells. J. Steroid Biochem. 118, 219-230. https://doi.org/10.1016/j.jsbmb.2009.09.018 (2010).

61. Yamada, K. et al. Cell surface localization of importin alpha 1/KPNA2 affects cancer cell proliferation by regulating FGF1 signalling. Sci. Rep. https://doi.org/10.1038/Srep21410 (2016).

62. Moriyama, T. et al. Identification and characterization of a nuclear localization signal of TRIM28 that overlaps with the HP1 box. Biochem. Biophys. Res. 462, 201-207. https://doi.org/10.1016/j.bbrc.2015.04.108 (2015).

63. Moriyama, T. et al. Two isoforms of TALDO1 generated by alternative translational initiation show differential nucleocytoplasmic distribution to regulate the global metabolic network. Sci. Rep. https://doi.org/10.1038/Srep34648 (2016).

64. Sekimoto, T., Imamoto, N., Nakajima, K., Hirano, T. \& Yoneda, Y. Extracellular signal-dependent nuclear import of Stat1 is mediated by nuclear pore-targeting complex formation with NPI-1, but not Rch1. Embo J. 16, 7067-7077. https://doi.org/10.1093/ emboj/16.23.7067 (1997).

65. Tsujii, A., Miyamoto, Y., Moriyama, T., Tsuchiya, Y., Obuse, C., Mizuguchi, K., Oka M., Yoneda, Y. Retinoblastoma-binding Protein 4-regulated Classical Nuclear Transport Is Involved in Cellular Senescence. J. Biol. Chem. 290(49), 29375-29388 (2015).

66. Ogawa, Y., Imamoto, N. Nuclear transport adapts to varying heat stress in a multistep mechanism. J. Cell Biol. 217(7), 2341-2352 (2018).

\section{Acknowledgements}

We are grateful to all members of the Department of Cell Biology \& Biochemistry (University of Fukui), Organization for Life Science Advancement Programs (University of Fukui), Life Science Research Laboratory (University of Fukui), Nuclear Transport Dynamics (NIBIOHN) and Biomolecular Dynamics Group (Osaka University). This work was supported in part by JSPS KAKENHI Grant Numbers (JP 18K15044, JP 26870341) (to T. M.), the Uehara Memorial Foundation, Takeda Science Foundation, the Naito Foundation, Terumo Life Science Foundation and Hoansha Foundation (to M. Y.).

\section{Author contributions}

T.M., Y.Y., M.O., and M.Y. conceived and designed the study and wrote the paper. All experiments were performed by T.M.

\section{Competing interests}

The authors declare no competing interests.

\section{Additional information}

Supplementary information is available for this paper at https://doi.org/10.1038/s41598-020-75631-3.

Correspondence and requests for materials should be addressed to M.Y. 
Reprints and permissions information is available at www.nature.com/reprints.

Publisher's note Springer Nature remains neutral with regard to jurisdictional claims in published maps and institutional affiliations.

(c) (i) Open Access This article is licensed under a Creative Commons Attribution 4.0 International License, which permits use, sharing, adaptation, distribution and reproduction in any medium or format, as long as you give appropriate credit to the original author(s) and the source, provide a link to the Creative Commons licence, and indicate if changes were made. The images or other third party material in this article are included in the article's Creative Commons licence, unless indicated otherwise in a credit line to the material. If material is not included in the article's Creative Commons licence and your intended use is not permitted by statutory regulation or exceeds the permitted use, you will need to obtain permission directly from the copyright holder. To view a copy of this licence, visit http://creativecommons.org/licenses/by/4.0/.

(C) The Author(s) 2020 